\title{
1 Impact of human airway epithelial cellular composition on SARS-CoV-2 infection
}

\section{2 biology}

4 Ying Wang, ${ }^{\mathrm{a}^{*}}$ Melissa Thaler, ${ }^{\mathrm{b}^{*}}$ Dennis K. Ninaber, ${ }^{\mathrm{a}}$ Anne M. van der Does, ${ }^{\mathrm{a}}$ Natacha S.

5 Ogando, ${ }^{\mathrm{b}}$ Hendrik Beckert, ${ }^{\mathrm{c}}$ Christian Taube, ${ }^{\mathrm{c}}$ Clarisse Salgado-Benvindo, ${ }^{\mathrm{b}}$ Eric J.

6 Snijder $^{\mathrm{b}}$, Peter J. Bredenbeek, ${ }^{\mathrm{b}}$ Pieter S. Hiemstra, ${ }^{\mathrm{a} \#}$ Martijn J. van Hemert ${ }^{\mathrm{b} * \#}$

$7 \quad{ }^{a}$ Department of Pulmonology, Leiden University Medical Center, Leiden, The

8 Netherlands.

$9{ }^{\mathrm{b}}$ Department of Medical Microbiology, Leiden University Medical Center, Leiden, The

10 Netherlands.

$11{ }^{\mathrm{c}}$ Department of Pulmonary Medicine, University Medical Center Essen - Ruhrlandklinik,

12 Essen, Germany

$13 *$ These authors contributed equally to this work.

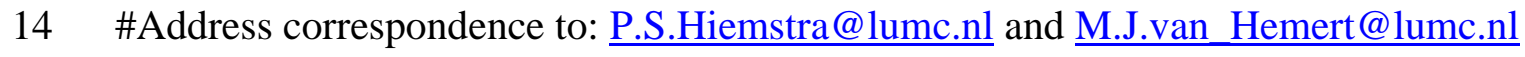

15 Pieter S. Hiemstra, PhD

16 Department of Pulmonology, Leiden University Medical Center, The Netherlands

17 e-mail: p.s.hiemstra@lumc.nl

18 or

19 Martijn J. van Hemert, $\mathrm{PhD}$

20 Department of Medical Microbiology, Leiden University Medical Center

21 e-mail: M.J.van_Hemert@lumc.nl

25 Running title: Impact of epithelial cellular composition on SARS-CoV-2 infection 
28 ABSTRACT Infection biology and pathogenesis of severe acute respiratory syndrome

29 coronavirus 2 (SARS-CoV-2), the causative agent of the coronavirus disease 2019

30 (COVID-19), are incompletely understood. Here, we assessed the impact of airway

31 epithelial cellular composition on infection in air-liquid interface (ALI) cultures of

32 differentiated primary human tracheal (PTEC) and bronchial epithelial cells (PBEC). We

33 first compared SARS-CoV-2 infection kinetics, related antiviral and inflammatory

34 responses, and viral entry factors in PTEC and PBEC. Next, the contribution of

35 differentiation time was investigated by differentiating ALI-PTEC/PBEC for 3-5 weeks

36 and comparing dynamics of viral replication/spread, cellular composition and epithelial

37 responses. We observed a gradual increase in viral load with prolonged culture duration.

38 Ciliated and goblet cells were predominantly infected in both PTEC and PBEC.

39 Immunofluorescence analysis and RT-qPCR showed that compared to other cell types

40 mainly ciliated and goblet cell numbers were affected by increased culture duration. An

41 increased proportion of these two target cell types was associated with increased viral

42 load. Furthermore, modulation of cellular composition using IL-13 and the Notch

43 signaling inhibitor DAPT, underlined the importance of both ciliated and goblet cells for

44 infection. DAPT treatment resulted in a lower viral load and a relative increase in ciliated

45 cells at the expense of goblet cells, compared to IL-13 treated cultures in which both cell

46 types were present and viral load was higher.

47 In conclusion, our results identify cellular composition as a contributing factor to airway

48 epithelial susceptibility to SARS-CoV-2. 
50 IMPORTANCE In this study, we determined an effect of culture duration and airway

51 cellular composition of ALI-PBEC and ALI-PTEC cultures on SARS-CoV-2 infection.

52 We found that SARS-CoV-2 infection was increased with prolonged cell culture time and

53 the total percentage and proportion of ciliated and goblet cells played an important role in

54 infection level, suggesting that airway epithelial differentiation/maturation levels may in

55 part determine susceptibility of SARS-CoV-2 infection.

56 The development of effective therapies either targeting virus replication or pathogenesis

57 against SARS-CoV-2 requires robust cell culture-based infection models to test small

58 molecules and biologicals. Therefore, it is important to identify factors that are essential

59 for reliably modeling SARS-CoV-2-airway epithelial cell interactions. This study sheds

60 light on virus-airway epithelial cell interactions and adds to the complexity of SARS-

61 CoV-2 cell tropism in the airways. In addition, the effect of IL-13 on viral infection hints

62 at a causal connection between SARS-CoV-2 infection and (allergic) asthma.

63

64 KEYWORDS SARS-CoV-2, human airway epithelial cells, infection biology,

65 differentiation, cellular composition 


\section{INTRODUCTION}

67 Since December 2019, severe acute respiratory syndrome coronavirus 2 (SARS-CoV-2)

68 has rapidly spread worldwide. The burden of the associated coronavirus disease 2019

69 (COVID-19) on human health has an enormous social and economic impact (1). In an

70 immense effort to combat COVID-19, several successful vaccines have been developed

71 and approved for large scale vaccination campaigns across the globe. However, there is

72 not yet a specific antiviral drug that was proven to be beneficial for relevant patient

73 outcomes. Furthermore, the emergence of virus variants, such as those first observed in

74 the United Kingdom, South Africa, Brazil and India (2-5), which are associated with a

75 rapid increase in COVID-19 cases $(6,7)$, illustrates the threat of these viruses to prolong

76 the current pandemic or lead to new large outbreaks in the future. These recent

77 developments also underscore the need to develop therapeutic options, which requires a

78 better understanding of SARS-CoV-2 infection biology and pathogenesis.

80 SARS-CoV-2 was first isolated from the lower respiratory tract of patients presenting

81 with COVID-19 $(8,9)$. The respiratory tract spans from the nasal cavity to the terminal

82 bronchioles. It is lined by the airway epithelium, which includes many cell types: mainly

83 ciliated, goblet, club and basal cells $(10,11)$. The epithelium serves as first barrier to

84 SARS-CoV-2 infection and therefore epithelial immune responses (antiviral responses,

85 inflammatory responses) play an important role in the outcome of infection. In vitro

86 cultures of Vero E6 cells, lung epithelial cell lines like Calu-3 cells, and differentiated

87 primary human bronchial epithelial cells have enabled studies on the kinetics of SARS-

88 CoV-2 infection in more detail $(12,13)$. Recent reports showed that SARS-CoV-2 targets

89 ciliated and secretory cells $(14,15)$, or ciliated cells with strands of mucus attached to the

90 cilia tips (16). SARS-CoV-2 cellular tropism depends on host proteins that are involved

91 in virus entry, including angiotensin converting enzyme 2 (ACE2) and proteases like

92 transmembrane protease serine 2 (TMPRSS2), as well as alternative receptors (cluster of

93 differentiation 147 [CD147], 78-kDa glucose-regulated protein [GRP78], tyrosine-protein

94 kinase receptor UFO [AXL]), which all have been demonstrated to be present in human

95 airway epithelial cells (17-20). The involvement of these and other factors in SARS-

96 CoV-2 infection biology and pathogenesis can be therefore studied in an in vitro model of 
97 human primary airway epithelial cells. However, the airway epithelium is a dynamic

98 system with cellular compositions that vary throughout the respiratory tract (10) and that

99 is in constant turnover (21). In addition, in many patients with lung diseases such as

100 asthma or chronic obstructive pulmonary disease (COPD), epithelial cellular composition

101 is altered (11). Cellular composition also can be modulated by other factors (e.g. the

102 Notch signaling inhibitor DAPT and the Th2 cytokine IL-13) in vitro (22-24). Since

103 SARS-CoV-2 was shown to target mainly ciliated and goblet cells, we hypothesized that

104 cellular composition of the airway epithelium affects SARS-CoV-2 infection and this

105 could contribute to regional and airway disease-associated differences in infection

106 biology as observed in human lungs.

107

108 To this end, we used primary human bronchial (PBEC) or tracheal epithelial cells (PTEC)

109 and differentiated them by culture at the air-liquid interface (ALI) to generate the cell

110 types that constitute the airway epithelium. We characterized virus replication, spread,

111 localization, immune responses, and expression of SARS-CoV-2-entry factors, as well as

112 compared cellular composition between both types of cultures. Furthermore, we

113 investigated how differences in culture and infection characteristics were influenced by

114 the duration of culturing and by modulation of the cellular composition using DAPT and

115 IL-13.

117 RESULTS

118 SARS-CoV-2 efficiently infects differentiated human primary bronchial epithelial

119 cells. To investigate the effect of differences in cellular composition on SARS-CoV-2

120 infection of airway epithelial cells, we first aimed to establish a reliable infection model.

121 Therefore, mixes of ALI-PBEC from 4 or 5 donors were differentiated for 5 weeks as

122 previously reported (14). By using mixes of primary cells from several donors (donor

123 mix) for optimization of our model, we aimed to limit the impact of possible inter-donor

124 variation, while maintaining the characteristics of using primary cells. We decided to

125 perform infections at a relatively low multiplicity of infection (MOI) to initially only

126 infect a fraction of susceptible cells and observe the virus spread across the epithelium 
127 through time. Four independent experiments were performed using ALI-PBEC derived

128 from the same donor mix. After infection with SARS-CoV-2 (30,000 PFU per insert), we

129 observed an increase in viral load (extracellular copies of viral RNA) over time, resulting

130 in about $10^{11}$ copies/ml at 72 hours post infection (hpi) (Fig. 1A). Immunofluorescence

131 staining of the epithelial cultures for viral nucleocapsid protein also showed an increase

132 in the number of infected cells over time (Fig. 1B). We next compared infection kinetics

133 in the donor mix and in cultures of the 4 individual donors that were used to establish the

134 mix. Single donor and mixed donor cultures showed comparable infection kinetics (Fig.

135 1C), and immunofluorescence staining also showed similar numbers of infected cells at

13672 hpi (Fig. 1D) thereby supporting the use of these donor mixes for our studies.

137 To validate the relevance of our cell culture model for studying the epithelial defense 138 against SARS-CoV-2 infection, we measured antiviral responses (IFN- $\beta 1$ and IFN- $\lambda 1$ ), 139 inflammatory cytokines [IL-6 and IL-8(CXCL8)] as well as expression of SARS-CoV-2140 entry factors (ACE2 and TMPRSS2) in the donor mix cultures. We observed that SARS141 CoV-2 infection did not affect mRNA levels of $I F N-B 1$ and $I F N-L 1$ at 24 and $48 \mathrm{~h}$, but 142 strongly increased their expression at $72 \mathrm{~h}$ post-infection (Fig. 1E and 1F). At 72 hpi, 143 mRNA levels of both $I L-6, I L-8$ and $A C E 2$ displayed a modest but significant increase in 144 SARS-CoV-2-infected cultures (Fig. 1G, H), while the expression of TMPRSS2 remained 145 unchanged (Fig. 1H). These findings show reproducible and robust infection kinetics in 146 our model, as well as a significant but late epithelial antiviral and inflammatory response 147 that is characteristic in SARS-CoV-2 infection (25). Using ALI-PBEC cultures of mixed 148 donor cells proved to be a practical way to investigate SARS-CoV-2 infection of airway 149 epithelial cell cultures in a model that incorporates genetic variation between individuals, 150 while limiting sample size to allow investigation of many variables.

152 Effect of culture duration of primary bronchial and tracheal epithelial cell cultures 153 on SARS-CoV-2 infection. We compared infection of ALI-PBEC and ALI-PTEC 154 cultures as these epithelial tissues differ in cellular composition as a result of their 155 disparate anatomical origin. To investigate if duration of the ALI culture has an effect on 156 the infection kinetics of SARS-CoV-2, we allowed ALI-PBEC and ALI-PTEC to 157 differentiate for 3, 4 or 5 weeks, after which they were infected with 30,000 PFU of 
158 SARS-CoV-2. Viral load was analyzed at 72 hpi (Fig. 2). In both ALI-PBEC and ALI-

159 PTEC, an increase in intra- and extracellular viral RNA as well as infectious virus

160 particles was observed with longer culture time, with the highest viral load observed at 5

161 weeks after ALI (Fig. 2A-2C). A gradual 1-2 log increase in SARS-CoV-2 progeny

162 production was observed from 3 to 5 weeks of differentiation when three independent

163 cultures of different PTEC and PBEC donor mixes were followed over time (Fig. S1).

164 This shows the robustness of our model and the reproducibility of our results, 165 independent of the ALI-PBEC or ALI-PTEC donor mix used. Immunofluorescence 166 staining of these cultures for the viral nucleocapsid protein also demonstrated an increase 167 in the number of infected cells with increasing culture duration (Fig. 2D). A significantly 168 higher viral load was observed in ALI-PBEC than in ALI-PTEC, with an average 10-fold 169 difference in extracellular SARS-CoV-2 RNA copies (Fig. 2A) and infectious progeny 170 (Fig. 2B), in particular in 5-week differentiated cultures.

171 In conclusion, our results show that the anatomical origin of the epithelial cells and the 172 culture duration have an effect on the levels of infection, suggesting that cellular 173 composition is a contributing factor. To further investigate this possibility, we identified

174 the cell types that were primarily infected by SARS-CoV-2 and assessed their abundance 175 with respect to culture duration.

177 SARS-CoV-2 primarily infects ciliated and goblet cells in primary human bronchial 178 and tracheal epithelial cell cultures. Previous studies have indicated that within the 179 human respiratory tract, predominantly ciliated cells, but also goblet cells of the airway 180 epithelium can be infected with SARS-CoV-2 (14), besides alveolar epithelial cells (26, 181 27). To assess if ciliated and goblet cells were also the target cells in our cultures, we 182 investigated the colocalization of the SARS-CoV-2 nucleocapsid protein with either 183 acetylated $\alpha$-tubulin as a marker for ciliated cells, or MUC5AC as a marker for goblet 184 cells.

185 We observed positive staining of the viral nucleocapsid protein in acetylated $\alpha$-tubulin186 positive ciliated cells in ALI-PBEC (Fig. 3A) and also in MUC5AC-positive goblet cells 187 (Fig. 3B), suggesting that both cell types are indeed infected by SARS-CoV-2. Similar 
188 results were obtained with ALI-PTEC (Fig. S2), indicating that goblet cells and ciliated

189 cells originating from both anatomical locations in the airways can be infected.

Cellular composition of primary human airway epithelial tissues differs depending

192 on time of culturing. Since we found that increased viral infection with prolonged 193 culture time and observed that SARS-CoV-2 targeted both ciliated and goblet cells, we

194 hypothesized that changes in cellular composition might account for these differences.

195 Therefore, we compared cellular composition between 2, 3, 4 and 5 week-differentiated 196 cultures, for the same donor mixes that were used for infection. The results showed that 197 the cultures were well-differentiated at all time points, showing expression of markers 198 related to all cell types (ciliated, goblet, club and basal cells) in ALI-PBEC and PTEC 199 (Fig. 4 and S3). However, there were differences in the proportions of goblet and ciliated 200 cells. Using FOXJ1 and acetylated $\alpha$-tubulin as markers for ciliated cells, we observed 201 that the percentage of FOXJ1-positive cells was significantly higher in ALI-PBEC after 5 202 weeks ALI culture compared to 3-week cultures. The percentage of ciliated cells was 203 significantly higher in ALI-PBEC than in ALI-PTEC at all culture durations (Fig. 4A and 204 4B). The change in the percentage of MUC5AC-positive goblet cells was not significant 205 over time in ALI-PBEC and ALI-PTEC (Fig. 4A and 4B). The sum of the percentage of 206 ciliated and goblet cells was higher in week 5 ALI-PBEC cultures compared to week 3 207 cultures, and it was also higher in ALI-PBEC than ALI-PTEC when 5-week cultures 208 were compared (Fig. 4B). These differences in the total proportion of both cell types 209 between PTEC and PBEC and between cultures of different duration correlated with 210 differences in virus levels (Fig. 2). Furthermore, mRNA levels of FOXJ1 were 211 significantly increased in 4 week ALI-PBEC compared to 3 week cultures, however they 212 did not further increase in 5 week cultures (Fig. 4C). In addition, FOXJ1 mRNA was 213 higher in 4/5-week ALI-PBEC cultures compared to 4/5-week PTEC cultures (Fig. 4C). 214 In line with these findings, MUC5AC mRNA levels were higher at week 5 in ALI-PTEC 215 cultures compared to week 3, and also higher than in week 5 ALI-PBEC (Fig. 4C). In 216 contrast, there was no significant difference in the expression of SCGB1A1 (club cell 217 marker) and TP63 (basal cell marker) (Fig. S3). These results suggest that despite the 218 early presence of transcripts which are specific for certain cell types, maturation of these 
219 cell types (which also requires expression at the protein level) continues for several

220 weeks in cultures at ALI. In addition to culture duration, difference of ciliated and goblet

221 cell markers between ALI-PBEC and ALI-PTEC indicated that the origin of the epithelial

222 cells (tracheal versus bronchial) also has an impact on epithelial cellular composition.

223 Epithelial cellular composition, and especially percentages of ciliated and goblet cells

224 were associated with increased SARS-CoV-2 infection. While the observed increase in

225 viral load cannot be attributed to one cell type alone, the levels of both ciliated and goblet

226 cells appear to affect infection outcome in our model.

Modulating epithelial cellular composition has moderate effects on SARS-CoV-2

229 infection. To further explore the association between epithelial cellular composition and 230 viral infection, we skewed differentiation of ALI-PBEC during the last 2 weeks of 231 culturing either towards an enrichment in ciliated cells, using the $\gamma$-secretase inhibitor 232 DAPT (that acts as an inhibitor of Notch signaling), or towards an enrichment in goblet 233 cells using interleukin 13 (IL-13) (22-24). We infected these cultures with SARS-CoV-2 234 to analyze if enrichment of one of the cell types impacted infection kinetics. We could 235 verify that DAPT treatment caused a marked increase in ciliated cells (FOXJ1 and 236 acetylated $\alpha$-tubulin positive) while the number of goblet cells (MUC5AC positive) was 237 decreased (Fig. 5A and S4A). Conversely, IL-13 treatment increased the fraction of 238 goblet cells and decreased the number of ciliated cells (Fig. 5A and S4A). This was 239 confirmed by quantifying expression levels of mRNAs that serve as markers for each cell 240 type (Fig. S4B). Although DAPT and IL-13 treatment caused a shift in the ratio between 241 ciliated and goblet cells, it did not change the combined/total number of these two cell 242 types (Fig. S4A). Notably, there were almost no goblet cells present in DAPT-treated 243 cultures.

244 We next infected the DAPT- or IL-13-treated cultures with SARS-CoV-2 and infection 245 kinetics were analyzed. In line with the data shown in Fig. 1, only a few infected cells 246 were identified at $24 \mathrm{hpi}$ in untreated and treated cultures by immunofluorescence 247 staining (Fig. 5B). At 48 hpi, DAPT-treated cell cultures showed a lower number of 248 infected cells compared to untreated or IL-13-treated cells (Fig. 5B). In untreated, DAPT249 and IL-13-treated cultures, spread of infection was observed and a substantial fraction of 
250 the cells was infected at $72 \mathrm{hpi}$, with IL-13-treated cell cultures displaying the highest

251 level of infected cells (Fig. 5B). The level of intracellular SARS-CoV-2 RNA was lower

252 in DAPT-treated cells at all time points compared to the controls (Fig. 5C). We did not

253 observe a significant decrease of infectious viral particles in DAPT-treated cultures (Fig.

254 5D). These findings suggested that a DAPT-induced increase in ciliated cells did not

255 enhance infection, but rather was associated with decreased viral replication or spread.

256 Treatment with IL-13 on the other hand showed a trend towards an increase in

257 intracellular copies and infectious virus particles compared to untreated and DAPT-

258 treated cultures (Fig. 5C and 5D).

259 To exclude the possibility that the effects observed in DAPT-treated cultures were a 260 direct consequence of inhibition of Notch signaling rather than epithelial remodeling, we 261 treated cells with DAPT either starting $24 \mathrm{~h}$ before (and during) infection (a time period 262 considered insufficient to cause a shift in epithelial differentiation) or directly after 263 infection. These 'short term treatments' with DAPT did not result in significant changes in 264 the amount of intracellular viral RNA copies or extracellular viral load, suggesting that 265 inhibition of Notch signaling has no direct effect on SARS-CoV-2 replication (Fig. S4C).

266 These findings indicate that the effects of DAPT treatment on infection are more likely 267 due to an effect on cellular composition.

269 Culture duration does not affect SARS-CoV-2-entry factors. Viral entry factors are 270 expressed by human airway epithelial cells and their expression varies between different 271 airway epithelial cell types (18). Since cells could be infected more efficiently when they 272 were allowed to differentiate for longer periods of time, we investigated if this could 273 (also) be related to changes in expression of receptors used by SARS-CoV-2 to enter the 274 cells. SARS-CoV-2 uses mainly ACE2 as its receptor, but studies demonstrated that other 275 co-factors can also determine its cellular tropism (19). We found that culture duration 276 did not affect gene expression of ACE2, TMPRSS2, CD147 and GRP78 (Fig. 6A) These 277 findings indicated that differences in susceptibility to SARS-CoV-2 infection between 278 ALI-PBEC and ALI-PTEC, and between 3-, 4- and 5-week differentiated cultures were 279 likely not due to differences in epithelial expression of SARS-CoV-2 cell entry-related 
genes. Furthermore, also treatment with DAPT or IL-13 did not markedly affect

281 expression of viral entry factors (Fig. 6B).

SARS-CoV-2-induced antiviral responses in primary human airway epithelial 284 cultures

285 Antiviral responses in the epithelium are critical for protection against viral infections.

286 Therefore, we investigated whether there were differences in antiviral responses

287 depending on the epithelial culture duration, which might explain the observed increased 288 susceptibility to infection with longer culture times. In ALI-PTEC, SARS-CoV-2-

289 induced mRNA levels of both IFNBI and IFNL1 increased significantly with culture 290 duration. When cultures were infected at week 3 or 4 there was little IFNB1 or IFNL1 291 mRNA produced, while expression of these genes was strongly upregulated by SARS292 CoV-2 infection in 5 week old cultures (Fig. 7A and 7B). Gene expression analysis of 293 IFNB1 and IFNL1 showed a similar increasing trend in ALI-PBEC upon infection (Fig. 294 7C and 7D). When 5-week PBEC were (long-term) treated with DAPT, we observed 295 lower SARS-CoV-2-induced antiviral responses than in untreated and IL-13-treated 296 cultures (Fig. 7E and 7F). All these findings correlate with the observed differences in the 297 number of infected cells and viral load resulting from culture duration and DAPT and IL-

29813 treatment (Fig. 5). This suggests that antiviral responses were likely not affected by 299 differentiation time or long-term DAPT/IL-13 treatment, but rather by a direct response 300 to the virus load.

\section{DISCUSSION}

304 Here we describe and characterize the use of well-differentiated human primary airway

305 epithelial cell cultures to investigate the effect of cell composition on susceptibility to 306 SARS-CoV-2 infection. Our key finding is that culture duration at the air-liquid interface, 307 which is needed to achieve mucociliary differentiation, is an important contributor to 308 SARS-CoV-2 infection kinetics. Specifically, the percentage of goblet and ciliated cells 309 is pivotal as these cell types are likely the first to become infected.

310 As a highly relevant cell model, cultures of well-differentiated airway epithelial cells are 311 employed to study infection biology of SARS-CoV-2. With regard to differentiation time, 
312 there is no consensus or standardized protocol for ALI-PBEC cultures and it is described

313 in literature as anywhere from 2 to 6 weeks after start of culture at the air-liquid interface

$314(14,15,28)$. To validate our model, we decided to use up to 5 weeks differentiated ALI-

315 PBEC cultures, in line with a recent study (14). In this study, we report efficient infection

316 with the peak of viral load at 72 hpi with around $10^{11}$ extracellular RNA copies and $10^{6}$

$317 \mathrm{PFU} / \mathrm{ml}$, and observed virus spread across the epithelium by immunofluorescence

318 staining of infected cells. The amount of viral progeny produced is in line with other

319 studies assessing viral load levels (14). We have established our findings using cultures

320 derived from single donors and mixes derived from multiple donors, as well as compared

321 primary bronchial and tracheal cell cultures. The viral load was previously reported to

322 plateau at $72 \mathrm{hpi}$ and onset of related antiviral responses as well as inflammation were

323 also delayed, and therefore we mainly focused on this time point for analyses $(14,15)$. In

324 this study, mRNA levels of $I L-6$ and $I L-8$ were significantly upregulated by SARS-CoV-

325 2, which is consistent with previous findings (29) and different from results found in

326 human bronchial epithelial cell line (16HBE) (30). These findings highlight the

327 importance of using well-differentiated cell models for SARS-CoV-2 infection.

328 Multiple variables can contribute to epithelial susceptibility to SARS-CoV-2 infection,

329 and here we hypothesized cellular composition as being one of them. Epithelial cellular

330 composition is inherently different throughout the human respiratory tract $(10,11)$.

331 Ciliated, goblet, club and basal cells are the main cell types of the airway epithelium,

332 which vary upon culturing due to different stages of differentiation (31). To elucidate the

333 impact of cellular composition on infection kinetics, we used ALI-PTEC and ALI-PBEC

334 cultured for 3, 4 or 5 weeks. Firstly, we measured higher viral loads in ALI-PBEC than in

335 ALI-PTEC. Furthermore, we found increased infection with prolonged culture duration in

336 PBEC and PTEC.

337 To investigate the role of cellular composition in these observations, we first assessed

338 which cells were infected by SARS-CoV-2. Recent studies looking into the cell tropism

339 of SARS-CoV-2 have shown infection of multiple epithelial cell types, among them

340 ciliated cells, goblet cells and club cells of the airway epithelium and type 2 alveolar

341 epithelial cells $(14,15,32,33)$. In line with other studies, we found that both ciliated and 
342 goblet cells were infected by SARS-CoV-2 in our ALI-PBEC and ALI-PTEC cultures,

343 suggesting both ciliated cells and goblet cells support viral replication.

344 We next compared cellular composition in ALI-PBEC and ALI-PTEC cultured for 3-5

345 weeks, and found that differences in ciliated and goblet cell numbers did not explain the

346 differences in infection. Our data suggest that the total percentages of target cells that

347 might be initially susceptible, i.e. ciliated and goblet cells, influences the efficiency of

348 infection. Interestingly, we also observed cells co-expressing markers of ciliated cells

349 (FOXJ1) and goblet cells (MUC5AC) in our culture. This specific cell population, which

350 was reported by e.g. Garcia et al. (31) and is suggested to represent a transitional state

351 between goblet cells and ciliated cells, was recently labeled as transient secretory cells

352 (34). Based on their relative high expression of ACE2 and TMPRSS2, Lukassen et al(34)

353 suggested that these transient secretory cells may be particularly vulnerable to SARS-

354 CoV-2 infection.

355 Unexpectedly, skewing differentiation towards ciliated cells by treatment of our cultures

356 with DAPT, actually decreased infection compared to untreated and IL-13-treated

357 cultures, highlighting the importance of the presence of goblet cells, besides ciliated cells.

358 Of note, there was a very weak signal of the goblet cell marker (MUC5AC) after

359 treatment with DAPT, and therefore, the presence of some goblet cells in these cultures

360 cannot be excluded. Another explanation would be that ciliated cells catch the viruses

361 through cilia, and mucus produced by goblet cells helps spread the infection after release

362 and therefore hinders clearance by ciliated cells, which would be consistent with previous

363 findings that SARS-CoV-2 infects mucus-covered ciliated cells (35). To exclude a

364 possible direct effect of DAPT treatment on viral replication via inhibition of Notch

365 signaling (36) independent of formation of ciliated cells, short-term treatment with DAPT

366 during infection was performed. However, such acute treatment did not alter viral

367 infection.

368 Conversely, (slightly) increased viral loads were observed in IL-13-treated cultures

369 compared to control and DAPT-treated cultures, in line with the suggestion that patients

370 with allergic asthma, a disease associated with IL-13-induced changes in epithelial cells,

371 may be somewhat more susceptible to SARS-CoV-2 infection (37). Collectively, these

372 observations indicate that DAPT- and IL-13-mediated modulation of epithelial cell 
373 differentiation does not provide a simple answer to linking differences in epithelial cell 374 composition to SARS-CoV-2 infectivity, but hints at the role of other factors like mucus 375 secretion of goblet cells (38), which could hinder clearance of the virus in the epithelium, 376 or ciliary (dys)functioning that may influence spread of the virus (39).

377 We excluded the possibility that the abundance of viral entry factors contributed to the 378 observed differences in SARS-CoV-2 replication/spread, as their expression was not 379 significantly higher in ALI-PBEC than ALI-PTEC and did not increase with the time of 380 differentiation. Zhang et al. showed that gene expression of ACE2 was increased in 381 differentiated ALI cultures compared to submerged cultured basal cells and that their 382 levels did not change during differentiation (28), which is in line with our findings. 383 Furthermore, DAPT treatment and IL-13 treatment did not change the levels of viral 384 entry factors in our study. However, recent studies showed that long-term IL-13 exposure 385 decreased, while DAPT increased ACE2-positive apical cells in nasal epithelial cell 386 cultures, differentiated for 3 weeks (40). Differences with our findings could be explained 387 by a possible discrepancy between mRNA and protein levels or differences in cell culture 388 duration.

389 Another factor that shapes infection is the antiviral response. Recent studies showed that 390 SARS-CoV-2 upregulated type III IFN (IFN- $\lambda 1)$ in human intestinal epithelial cells and 391 an organoid-derived bronchioalveolar model (relatively late in infection) (25, 41). 392 Importantly, addition of type III IFN- $\lambda 1$ inhibited SARS-CoV-2 infection in human Calu3933 and simian Vero E6 cells in a dose dependent manner (42). In this study, we found that 394 expression of type I and III IFNs showed a similar pattern as viral replication over culture 395 time in ALI cultures, which indicated that antiviral responses may not contribute to the 396 gradual increase in viral infection with prolonged culture time.

397 Our comparison of mixed donor cultures to cultures of single donors showed similar 398 infection kinetics, which is in line with our previous findings (12). This demonstrates that 399 the use of mixed donor cultures is an efficient way to recapitulate natural variability 400 between donors while saving on resources (cells, culture plastics and media) that are in 401 high demand/short supply. The level of donor-to-donor variation was also represented in 402 inter-experimental variation when using the same donor mix. However, there are also 403 some limitations in this study, like the sources of cells. PBEC were derived from tumor- 
404 free resected bronchial tissue from (ex-)smoking non-COPD patients with lung cancer,

405 and PTEC were from lung donors without lung disease, which may have affected the

406 comparison between PBEC and PTEC.

408 In summary, we show that culture time of airway epithelial cells at the air-liquid interface 409 is a determinant of their susceptibility to SARS-CoV-2 infection, which can only be

410 partly explained by differentiation status based on the amount of ciliated and goblet cells.

411 Differences in expression of entry-associated factors, like ACE2 or TMPRSS2 do not

412 explain the increased susceptibility of airway epithelial cell cultures upon prolonged

413 culture. Our observation that IL-13 treatment causes a limited increase in SARS-CoV-2

414 infection may be relevant for understanding the impact of type 2 allergic inflammation on

415 SARS-CoV-2 susceptibility. Decreased infection following prolonged inhibition of Notch

416 signaling by DAPT highlights the importance of the presence of both ciliated and goblet

417 cells and warrants further investigation. Ultimately, cellular maturation/differentiation

418 seems intertwined with virus load and spread of the infection over the culture. The

419 proposed cell culture set-up provides a robust tool to test antiviral compounds and

420 acquire additional insight into infection biology of SARS-CoV-2.

\section{MATERIALS AND METHODS}

424 Cell culture. PBEC were isolated from tumor-free resected bronchial tissue that was 425 obtained from patients undergoing resection surgery for lung cancer at the Leiden 426 University Medical Center (Leiden, the Netherlands). Use of such lung tissue that became 427 available for research within the framework of patient care was in line with the "Human 428 Tissue and Medical Research: Code of conduct for responsible use" (2011) 429 (www.federa.org), that describes the opt-out system for coded anonymous further use of 430 such tissue. PTEC were isolated from residual tracheal and main stem bronchial tissue 431 from lung transplant donors post-mortem at the University Medical Center Essen (Essen, 432 Germany). Use of such donor tissue for research was approved by the ethical committee 433 of the Medical faculty of the University Duisburg-Essen (ID: 19-8717-BO). After 
434 isolation, cells were expanded in T75 flasks and frozen in liquid nitrogen until use as 435 previously described (43).

436 To achieve mucociliary differentiation, primary human bronchial/tracheal epithelial cells 437 were cultured at the air-liquid interface (ALI) as previously described (22). Briefly, 438 approximately 150,000 cells (30,000 cells/donor when mixing cells from 5 donors and 43940,000 cells/donor when using 4 donors) were seeded onto 12-insert Transwell 440 membranes (Corning Costar, Cambridge, MA, USA), which were coated with PBS 441 supplemented with $5 \mu \mathrm{g} / \mathrm{ml}$ human fibronectin (Promocell, Heidelberg, Germany), 30 $442 \mu \mathrm{g} / \mathrm{ml}$ PureCol (Advanced BioMatrix, CA, USA) and $10 \mu \mathrm{g} / \mathrm{ml}$ bovine serum albumin 443 (Fraction V; Thermo Fisher Scientific, Carlsbad, CA, USA), in a 1:1 mixture of 444 Bronchial Epithelial Cell Medium-basal (BEpiCM-b; ScienCell, Sanbio) and Dulbecco's 445 modified Eagle's medium (DMEM) (Stemcell Technologies, Köln, Germany), further 446 referred to as B/D medium. This B/D medium contains $12.5 \mathrm{mM}$ Hepes, bronchial 447 epithelial cell growth supplement, $100 \mathrm{U} / \mathrm{ml}$ penicillin, $100 \mathrm{ug} / \mathrm{ml}$ streptomycin (all from 448 ScienCell), 2 mM glutaMAX (Thermo Fisher Scientific). B/D medium was supplemented 449 during submerged culture with 1 nM EC23 (light-stable retinoic acid receptor agonist; 450 Tocris, Abingdon, UK). After confluence was reached, the apical medium was removed 451 and cells were cultured at the ALI in B/D medium with $50 \mathrm{nM} \mathrm{EC23} \mathrm{for} \mathrm{3-5} \mathrm{weeks,}$ 452 medium was refreshed and the apical side was washed three times a week with warm 453 PBS to remove excess mucus.

454 PBEC (40,000 cells) from the individual donors were expanded in separate cultures, 455 before mixing all donors when seeding them on inserts. For these donor mixes, higher 456 cell numbers for plating on inserts were used when compared to using individual donors 457 to avoid selective advantage of possible faster-proliferating cells of specific donors.

458 To shift cell differentiation towards an increased number of goblet or ciliated cells, ALI459 PBEC were incubated in BD medium supplemented with $50 \mathrm{nM}$ EC23, and either 1 $460 \mathrm{ng} / \mathrm{ml}$ IL-13 (Peprotech) or $5 \mu \mathrm{M}$ DAPT ( $\gamma$-secretase inhibitor, TOCRIS) from day 22 to 461 day 35 culture time.

462 For acute treatment of DAPT, ALI-PBEC after 5 week culture were either pre-treated 463 with DAPT $(5 \mu \mathrm{M})$ for 24 hpi or DAPT was directly added $(5 \mu \mathrm{M})$ after infection. 
464 Vero E6 cells (master stock MM-3 from dept of Medical Microbiology collection, 465 characterized by full genome sequencing) were maintained in Dulbecco's modified 466 Eagle's medium with $4.5 \mathrm{~g} / \mathrm{l}$ glucose with L-Glutamin (DMEM; Lonza), supplemented 467 with $8 \%$ fetal calf serum (FBS; CapriCorn Scientific) and $100 \mathrm{U} / \mathrm{ml}$ of 468 penicillin/streptomycin (Sigma-Aldrich). All cell cultures were maintained at $37^{\circ} \mathrm{C}$. 469 Infections for plaque assay in Vero E6 cells were performed in Eagle's minimal essential 470 medium with 25 mM HEPES (EMEM; Lonza) supplemented with 2\% FCS, 2 mM L471 glutamine (Sigma-Aldrich), and $100 \mathrm{U} / \mathrm{ml}$ of penicillin/streptomycin (Sigma-Aldrich) .

473 SARS-CoV-2 virus. The clinical isolate SARS-CoV-2/Leiden-0002 was isolated from a 474 nasopharyngeal sample collected at the LUMC (GenBank accession nr. MT510999). 475 Then, SARS-CoV-2/Leiden-0002 was passaged twice in Vero E6 cells to obtain the virus 476 stock used for infection. Virus titers were determined by plaque assay as described before 477 (44). All experiments with infectious SARS-CoV-2 were performed at the Leiden 478 University Medical Center biosafety level 3 facilities.

480 SARS-COV-2 infection of ALI-PBEC. Prior to infection, excess of mucus was removed 481 by washing the apical surface of the ALI cultures with $200 \mu 1$ PBS and aspirating it after 482 a $10-$ min incubation at $37^{\circ} \mathrm{C}$. Basal medium was changed every two days. Cells were 483 infected with $200 \mu \mathrm{l}$ of inoculum prepared in PBS, containing 30,000 PFU of SARS$484 \mathrm{CoV}-2$, per insert for $2 \mathrm{~h}$ at $37^{\circ} \mathrm{C}$ on a rocking platform (estimated MOI of 0.03). PBS 485 was used as a solvent control and in mock-infected cells as inoculum. After removal of 486 the inoculum, the apical side was washed three times with PBS. Then, cells were 487 incubated at $37^{\circ} \mathrm{C}$. Viral progeny was harvested from the apical side at $24 \mathrm{~h}, 48 \mathrm{~h}$ and 488 72h.p.i. as indicated below. Cells were infected after 3 to 5 weeks of differentiation as 489 indicated. For cells under DAPT or IL-13 treatment, the medium was supplemented with $4901 \mathrm{ng} / \mathrm{ml}$ IL-13 or $5 \mu \mathrm{M}$ DAPT after 2 weeks of differentiation, and after 5-week culture 491 time cells were infected. After infection, the basal medium was replaced by fresh B/D 492 medium also supplemented with IL-13 or DAPT. 

analysis. Apical washes were harvested following incubation at $37^{\circ} \mathrm{C}$ with $200 \mu \mathrm{PBS}$ (10 $\mathrm{min}$ ) and subsequent addition of $800 \mathrm{ul}$ of the TriPure Isolation Reagent (SigmaAldrich) to half of apical washes. Tripure reagent was spiked with Equine arteritis virus (EAV) to control for variation in RNA extraction efficiency and possible inhibitors of RT-qPCR. Intracellular RNA was isolated by adding $500 \mathrm{ul}$ of TriPure reagent directly onto the insert. Samples were stored at $-20^{\circ} \mathrm{C}$ until RNA was isolated using the Direct$\mathrm{zol}^{\mathrm{TM}}$-96 RNA plate isolation (Zymo), 5PRIME Phase Lock Gel extraction (Quantabio) or Maxwell@ 16 simply RNA tissue kit (Promega, the Netherlands). The cellular

503 reference gene PGK-1 was used as a house-keeping gene for intracellular RNA. Primers

504 and probes for EAV and PGK-1 and the normalization procedure was performed as 505 described before (44). Viral RNA was quantified by RT-qPCR using the TaqMan ${ }^{\mathrm{TM}}$ Fast 506 Virus 1-Step Master Mix (Thermo Fisher Scientific). Primers and probes were used as 507 described previously (45), but with modifications as listed in Table 1. A standard curve generated by RT-qPCR on 10-fold serial dilutions of a T7 RNA polymerase-generated in vitro transcript containing the target sequences was used for absolute quantification of RNA copy numbers. For other gene expression analysis, RNA was reverse-transcribed

512 using specific primers. Relative normalized gene expression compared to reference genes 513 Ribosomal Protein L13a (RPL13A) and ATP synthase, $\mathrm{H}^{+}$transporting, mitochondrial F1

514 complex, beta polypeptide (ATP5B) were calculated according to the standard curve 515 method. Reference genes were selected out of 8 candidate reference genes using the 516 "Genorm” software (Genorm; Primer Design, Southampton, UK). A RT-qPCR program

517 for both RNA copy numbers and host genes of $5 \mathrm{~min}$ at $50^{\circ} \mathrm{C}$ and $20 \mathrm{~s}$ at $95^{\circ} \mathrm{C}$ or direct 3

518 min at $95^{\circ} \mathrm{C}$, followed by 45 cycles of $5 \mathrm{~s}$ at $95^{\circ} \mathrm{C}$ and $30 \mathrm{~s}$ at $60^{\circ} \mathrm{C}$ or $63^{\circ} \mathrm{C}$ (optimal

519 temperature depending on primers), was performed on a CFX384 Touch ${ }^{\mathrm{TM}}$ Real-Time

520 PCR Detection System (Bio-Rad). Primer pairs are listed in Table 1.

521 For quantification of the number of infectious virus particles, the apical wash was serially

522 diluted and infectious titers were determined by plaque assay on Vero E6 as described

523 before (44). 
525 Immunofluorescence staining. ALI cultures were rinsed using PBS and cells were fixed 526 by adding $3 \%(\mathrm{w} / \mathrm{v})$ paraformaldehyde diluted in PBS into the basal and apical 527 compartments followed by incubation at room temperature for at least $35 \mathrm{~min}$. Next, 528 inserts were washed two times with PBS and stored in PBS with $10 \mathrm{mM}$ glycine at $4{ }^{\circ} \mathrm{C}$ 529 until further use. Ice-cold methanol was added for $10 \mathrm{~min}$ at $4^{\circ} \mathrm{C}$, and PBS containing $1 \%$ 530 (w/v) BSA, $0.3 \%$ (w/v) Triton-X-100 (PBT) was used to block non-specific binding sites 531 and permeabilize cells for $30 \mathrm{~min}$ at $4^{\circ} \mathrm{C}$. Membranes were excised from the insert and 532 cut into 4 pieces that were incubated overnight at $4^{\circ} \mathrm{C}$ with specific antibodies at the 533 following dilutions: rabbit anti-SARS-CoV-2 N antibody (JUC3,1:500, (46)), mouse anti534 MUC5AC antibody (1:200; Thermo Fisher Scientific), mouse anti-acetylated $\alpha$-tubulin 535 (1/100; Sigma Aldrich) or goat anti-FOXJ1 antibody (1:200; R\&D, Minneapolis, MN, 536 USA). After washing, membranes were incubated with corresponding secondary 537 antibodies: donkey anti-rabbit, donkey anti-mouse or donkey anti-goat Alexa-fluor 538 antibodies (all diluted 1:200, Thermo Fisher Scientific) and 4',6-diamidino-2539 phenylindole (DAPI, 1:200, Sigma-Aldrich) in the dark for $30 \mathrm{~min}$ at room temperature.

540 Next, membranes were transferred to glass slides and covered with prolong gold anti541 fading reagent (Thermo Fisher Scientific) and a coverslip (VWR, Amsterdam, the 542 Netherlands). Slides were viewed using a Leica TCS SP8 confocal microscope (Leica 543 Microsystems, Wetzlar, Germany) at 100 x /400 x / 630 x original magnification 544 according to experimental requirements.

\section{Acknowledgements}

548 This study was supported by a COVID-19 MKMD grant from the Netherlands

549 Organisation for Health Research and Development (ZonMw) and the Dutch Society for 550 the Replacement of Animal Testing (Stichting Proefdiervrij) (grant \#114025007).

551 C.S.-B. was supported by the Coordination for the Improvement of Higher Education 552 Personnel (CAPES) (process no. 88881.171440/2018-01), Ministry of Education, Brazil. 553 Part of this research was supported by the Leiden University Fund (LUF), the Bontius 554 Foundation, and donations from the crowdfunding initiative "wake up to corona". 
bioRxiv preprint doi: https://doi.org/10.1101/2021.07.21.453304; this version posted July 22, 2021. The copyright holder for this preprint (which

was not certified by peer review) is the author/funder, who has granted bioRxiv a license to display the preprint in perpetuity. It is made available under aCC-BY-NC-ND 4.0 International license.

555 Collection of primary human tracheal epithelial cells was supported by grants from the

556 Deutsche Forschungsgemeinschaft (DFG) (Ta 275/7-1 and Ta 275/8-1) to C.T.

557

558

559 


\section{References}

562 1. Chakraborty I, Maity P. 2020. COVID-19 outbreak: Migration, effects on society,

563 global environment and prevention. Sci Total Environ 728:138882.

5642 2. ECDC. 2020. Risk related to spread of new SARS-CoV-2 variants of concern in 565 the EU/EEA.

$5663 . \quad$ Kirby T. 2021. New variant of SARS-CoV-2 in UK causes surge of COVID-19. Lancet Respir Med 9:e20-e21.

4. Feder KA, Pearlowitz M, Goode A, Duwell M, Williams TW, Chen-Carrington PA, Patel A, Dominguez C, Keller EN, Klein L, Rivera-Colon A, Mostafa HH, Morris CP, Patel N, Schauer AM, Myers R, Blythe D, Feldman KA. 2021. Linked Clusters of SARS-CoV-2 Variant B.1.351 - Maryland, January-February 2021. MMWR Morb Mortal Wkly Rep 70:627-631.

5. Mallapaty S. 2021. India's massive COVID surge puzzles scientists. Nature 592:667-668.

6. Yurkovetskiy L, Wang X, Pascal KE, Tomkins-Tinch C, Nyalile TP, Wang Y, Baum A, Diehl WE, Dauphin A, Carbone C, Veinotte K, Egri SB, Schaffner SF, Lemieux JE, Munro JB, Rafique A, Barve A, Sabeti PC, Kyratsous CA, Dudkina NV, Shen K, Luban J. 2020. Structural and Functional Analysis of the D614G SARS-CoV-2 Spike Protein Variant. Cell 183:739-751.e8.

7. Toyoshima Y, Nemoto K, Matsumoto S, Nakamura Y, Kiyotani K. 2020. SARSCoV-2 genomic variations associated with mortality rate of COVID-19. J Hum Genet 65:1075-1082.

8. Park SE. 2020. Epidemiology, virology, and clinical features of severe acute respiratory syndrome -coronavirus-2 (SARS-CoV-2; Coronavirus Disease-19). Clin Exp Pediatr 63:119-124.

9. Zhou P, Yang X-L, Wang X-G, Hu B, Zhang L, Zhang W, Si H-R, Zhu Y, Li B, Huang C-L, Chen H-D, Chen J, Luo Y, Guo H, Jiang R-D, Liu M-Q, Chen Y, Shen X-R, Wang X, Zheng X-S, Zhao K, Chen Q-J, Deng F, Liu L-L, Yan B, Zhan F-X, Wang Y-Y, Xiao G-F, Shi Z-L. 2020. A pneumonia outbreak associated with a new coronavirus of probable bat origin. Nature 579:270-273.

10. Iwasaki A, Foxman EF, Molony RD. 2017. Early local immune defences in the respiratory tract. Nat Rev Immunol 17:7-20.

11. Hiemstra PS, McCray PB, Jr., Bals R. 2015. The innate immune function of airway epithelial cells in inflammatory lung disease. Eur Respir J 45:1150-62.

12. Salgado-Benvindo C, Thaler M, Tas A, Ogando NS, Bredenbeek PJ, Ninaber DK, Wang Y, Hiemstra PS, Snijder EJ, van Hemert MJ. 2020. Suramin Inhibits SARS-CoV-2 Infection in Cell Culture by Interfering with Early Steps of the Replication Cycle. Antimicrob Agents Chemother 64.

13. Ogando NS, Dalebout TJ, Zevenhoven-Dobbe JC, Limpens R, van der Meer Y, Caly L, Druce J, de Vries JJC, Kikkert M, Bárcena M, Sidorov I, Snijder EJ. 2020. SARS-coronavirus-2 replication in Vero E6 cells: replication kinetics, rapid adaptation and cytopathology. J Gen Virol 101:925-940.

604 Zhu N, Wang W, Liu Z, Liang C, Wang W, Ye F, Huang B, Zhao L, Wang H, Zhou W, Deng Y, Mao L, Su C, Qiang G, Jiang T, Zhao J, Wu G, Song J, Tan W. 
2020. Morphogenesis and cytopathic effect of SARS-CoV-2 infection in human airway epithelial cells. Nat Commun 11:3910.

15. Hao S, Ning K, Kuz CA, Vorhies K, Yan Z, Qiu J. 2020. Long-Term Modeling of SARS-CoV-2 Infection of In Vitro Cultured Polarized Human Airway Epithelium. mBio 11.

16. Ehre C. 2020. SARS-CoV-2 Infection of Airway Cells. N Engl J Med 383:969.

17. Hoffmann M, Kleine-Weber H, Schroeder S, Krüger N, Herrler T, Erichsen S, Schiergens TS, Herrler G, Wu NH, Nitsche A, Müller MA, Drosten C, Pöhlmann S. 2020. SARS-CoV-2 Cell Entry Depends on ACE2 and TMPRSS2 and Is Blocked by a Clinically Proven Protease Inhibitor. Cell 181:271-280.e8.

18. Sungnak W, Huang N, Bécavin C, Berg M, Queen R, Litvinukova M, TalaveraLópez C, Maatz H, Reichart D, Sampaziotis F, Worlock KB, Yoshida M, Barnes JL. 2020. SARS-CoV-2 entry factors are highly expressed in nasal epithelial cells together with innate immune genes. Nat Med 26:681-687.

19. Aguiar JA, Tremblay BJ, Mansfield MJ, Woody O, Lobb B, Banerjee A, Chandiramohan A, Tiessen N, Cao Q, Dvorkin-Gheva A, Revill S, Miller MS, Carlsten C, Organ L, Joseph C, John A, Hanson P, Austin RC, McManus BM, Jenkins G, Mossman K, Ask K, Doxey AC, Hirota JA. 2020. Gene expression and in situ protein profiling of candidate SARS-CoV-2 receptors in human airway epithelial cells and lung tissue. Eur Respir J 56.

20. Wang S, Qiu Z, Hou Y, Deng X, Xu W, Zheng T, Wu P, Xie S, Bian W, Zhang C, Sun Z, Liu K, Shan C, Lin A, Jiang S, Xie Y, Zhou Q, Lu L, Huang J, Li X. 2021. AXL is a candidate receptor for SARS-CoV-2 that promotes infection of pulmonary and bronchial epithelial cells. Cell Research doi:10.1038/s41422-02000460-y.

21. Ganesan S, Sajjan US. 2013. Repair and Remodeling of airway epithelium after injury in Chronic Obstructive Pulmonary Disease. Curr Respir Care Rep 2.

22. Wang Y, Ninaber DK, van Schadewijk A, Hiemstra PS. 2020. Tiotropium and Fluticasone Inhibit Rhinovirus-Induced Mucin Production via Multiple Mechanisms in Differentiated Airway Epithelial Cells. Front Cell Infect Microbiol 10:278.

23. Amatngalim GD, Schrumpf JA, Dishchekenian F, Mertens TCJ, Ninaber DK, van der Linden AC, Pilette C, Taube C, Hiemstra PS, van der Does AM. 2018. Aberrant epithelial differentiation by cigarette smoke dysregulates respiratory host defence. Eur Respir J 51.

24. Mertens TCJ, van der Does AM, Kistemaker LE, Ninaber DK, Taube C, Hiemstra PS. 2017. Cigarette smoke differentially affects IL-13-induced gene expression in human airway epithelial cells. Physiol Rep 5.

25. Lamers MM, van der Vaart J, Knoops K, Riesebosch S, Breugem TI, Mykytyn AZ, Beumer J, Schipper D, Bezstarosti K, Koopman CD, Groen N, Ravelli RBG, Duimel HQ, Demmers JAA, Verjans G, Koopmans MPG, Muraro MJ, Peters PJ, Clevers H, Haagmans BL. 2020. An Organoid-derived Bronchioalveolar Model for SARS-CoV-2 Infection of Human Alveolar-type II-like Cells. Embo j doi:10.15252/embj.2020105912:e105912.

26. Katsura H, Sontake V, Tata A, Kobayashi Y, Edwards CE, Heaton BE, Konkimalla A, Asakura T, Mikami Y, Fritch EJ, Lee PJ, Heaton NS, Boucher RC, 
693

694

Randell SH, Baric RS, Tata PR. 2020. Human Lung Stem Cell-Based Alveolospheres Provide Insights into SARS-CoV-2-Mediated Interferon Responses and Pneumocyte Dysfunction. Cell Stem Cell 27:890-904.e8.

27. Huang J, Hume AJ, Abo KM, Werder RB, Villacorta-Martin C, Alysandratos KD, Beermann ML, Simone-Roach C, Lindstrom-Vautrin J, Olejnik J, Suder EL, Bullitt E, Hinds A, Sharma A, Bosmann M, Wang R, Hawkins F, Burks EJ, Saeed M, Wilson AA, Mühlberger E, Kotton DN. 2020. SARS-CoV-2 Infection of Pluripotent Stem Cell-Derived Human Lung Alveolar Type 2 Cells Elicits a Rapid Epithelial-Intrinsic Inflammatory Response. Cell Stem Cell 27:962-973.e7.

28. Zhang H, Rostami MR, Leopold PL, Mezey JG, O'Beirne SL, Strulovici-Barel Y, Crystal RG. 2020. Expression of the SARS-CoV-2 ACE2 Receptor in the Human Airway Epithelium. Am J Respir Crit Care Med 202:219-229.

29. Vanderheiden A, Ralfs P, Chirkova T, Upadhyay AA, Zimmerman MG, Bedoya S, Aoued H, Tharp GM, Pellegrini KL, Manfredi C, Sorscher E, Mainou B, Lobby JL, Kohlmeier JE, Lowen AC, Shi PY, Menachery VD, Anderson LJ, Grakoui A, Bosinger SE, Suthar MS. 2020. Type I and Type III Interferons Restrict SARS-CoV-2 Infection of Human Airway Epithelial Cultures. J Virol 94. 30. Liao Y, Li X, Mou T, Zhou X, Li D, Wang L, Zhang Y, Dong X, Zheng H, Guo L, Liang Y, Jiang G, Fan S, Xu X, Xie Z, Chen H, Liu L, Li Q. 2020. Distinct infection process of SARS-CoV-2 in human bronchial epithelial cell lines. J Med Virol 92:2830-2838.

31. Ruiz García S, Deprez M, Lebrigand K, Cavard A, Paquet A, Arguel MJ, Magnone V, Truchi M, Caballero I, Leroy S, Marquette CH, Marcet B, Barbry P, Zaragosi LE. 2019. Novel dynamics of human mucociliary differentiation revealed by single-cell RNA sequencing of nasal epithelial cultures. Development 146.

32. Ziegler CGK, Allon SJ, Nyquist SK, Mbano IM, Miao VN, Tzouanas CN, Cao Y, Yousif AS, Bals J, Hauser BM, Feldman J, Muus C, Wadsworth MH, II, Kazer SW, Hughes TK, Doran B, Gatter GJ, Vukovic M, Taliaferro F, Mead BE, Guo Z, Wang JP, Gras D, Plaisant M, Ansari M, Angelidis I, Adler H, Sucre JMS, Taylor CJ, Lin B, Waghray A, Mitsialis V, Dwyer DF, Buchheit KM, Boyce JA, Barrett NA, Laidlaw TM, Carroll SL, Colonna L, Tkachev V, Peterson CW, Yu A, Zheng HB, Gideon HP, Winchell CG, Lin PL, Bingle CD, Snapper SB, Kropski JA, Theis FJ, et al. 2020. SARS-CoV-2 Receptor ACE2 Is an Interferon-Stimulated Gene in Human Airway Epithelial Cells and Is Detected in Specific Cell Subsets across Tissues. Cell 181:1016-1035.e19.

33. Bost P, Giladi A, Liu Y, Bendjelal Y, Xu G, David E, Blecher-Gonen R, Cohen M, Medaglia C, Li H, Deczkowska A, Zhang S, Schwikowski B, Zhang Z, Amit I. 2020. Host-Viral Infection Maps Reveal Signatures of Severe COVID-19 Patients. Cell 181:1475-1488.e12.

34. Lukassen S, Chua RL, Trefzer T, Kahn NC, Schneider MA, Muley T, Winter H, Meister M, Veith C, Boots AW, Hennig BP, Kreuter M, Conrad C, Eils R. 2020. SARS-CoV-2 receptor ACE2 and TMPRSS2 are primarily expressed in bronchial transient secretory cells. Embo j 39:e105114. 
695

35. Kimura H, Francisco D, Conway M, Martinez FD, Vercelli D, Polverino F, Billheimer D, Kraft M. 2020. Type 2 inflammation modulates ACE2 and TMPRSS2 in airway epithelial cells. J Allergy Clin Immunol 146:80-88.e8.

36. Keewan E, Beg S, Naser SA. 2021. Anti-TNF- $\alpha$ agents Modulate SARS-CoV-2 Receptors and Increase the Risk of Infection Through Notch-1 Signaling. Front Immunol 12:641295.

37. Eger K, Bel EH. 2021. Asthma and COVID-19: do we finally have answers? Eur Respir J 57.

38. Liu Y, Lv J, Liu J, Li M, Xie J, Lv Q, Deng W, Zhou N, Zhou Y, Song J, Wang P, Qin C, Tong WM, Huang B. 2020. Mucus production stimulated by IFN-AhR signaling triggers hypoxia of COVID-19. Cell Res 30:1078-1087.

39. Robinot R, Hubert M, de Melo GD, Lazarini F, Bruel T, Smith N, Levallois S, Larrous F, Fernandes J, Gellenoncourt S, Rigaud S, Gorgette O, Thouvenot C, Trébeau C, Mallet A, Duménil G, Gobaa S, Etournay R, Lledo P-M, Lecuit M, Bourhy H, Duffy D, Michel V, Schwartz O, Chakrabarti LA. 2020. SARS-CoV-2 infection damages airway motile cilia and impairs mucociliary clearance. bioRxiv doi:10.1101/2020.10.06.328369:2020.10.06.328369.

40. Sajuthi SP, DeFord P, Li Y, Jackson ND, Montgomery MT, Everman JL, Rios CL, Pruesse E, Nolin JD, Plender EG, Wechsler ME, Mak ACY, Eng C, Salazar S, Medina V, Wohlford EM, Huntsman S, Nickerson DA, Germer S, Zody MC, Abecasis G, Kang HM, Rice KM, Kumar R, Oh S, Rodriguez-Santana J, Burchard EG, Seibold MA. 2020. Type 2 and interferon inflammation regulate SARS-CoV-2 entry factor expression in the airway epithelium. Nat Commun 11:5139.

41. Stanifer ML, Kee C, Cortese M, Zumaran CM, Triana S, Mukenhirn M, Kraeusslich HG, Alexandrov T, Bartenschlager R, Boulant S. 2020. Critical Role of Type III Interferon in Controlling SARS-CoV-2 Infection in Human Intestinal Epithelial Cells. Cell Rep 32:107863.

42. Felgenhauer U, Schoen A, Gad HH, Hartmann R, Schaubmar AR, Failing K, Drosten C, Weber F. 2020. Inhibition of SARS-CoV-2 by type I and type III interferons. J Biol Chem 295:13958-13964.

43. Schrumpf JA, Ninaber DK, van der Does AM, Hiemstra PS. 2020. TGF- $\beta 1$ Impairs Vitamin D-Induced and Constitutive Airway Epithelial Host Defense Mechanisms. Journal of innate immunity 12:74-89.

44. Kovacikova K, Morren BM, Tas A, Albulescu IC, van Rijswijk R, Jarhad DB, Shin YS, Jang MH, Kim G, Lee HW, Jeong LS, Snijder EJ, van Hemert MJ. 2020. 6'- $\beta$-Fluoro-Homoaristeromycin and 6'-Fluoro-Homoneplanocin A Are Potent Inhibitors of Chikungunya Virus Replication through Their Direct Effect on Viral Nonstructural Protein 1. Antimicrob Agents Chemother 64.

45. Corman VM, Landt O, Kaiser M, Molenkamp R, Meijer A, Chu DK, Bleicker T, Brünink S, Schneider J, Schmidt ML, Mulders DG, Haagmans BL, van der Veer B, van den Brink S, Wijsman L, Goderski G, Romette JL, Ellis J, Zambon M, Peiris M, Goossens H, Reusken C, Koopmans MP, Drosten C. 2020. Detection of 2019 novel coronavirus (2019-nCoV) by real-time RT-PCR. Euro Surveill 25.

46. de Wilde AH, Raj VS, Oudshoorn D, Bestebroer TM, van Nieuwkoop S, Limpens R, Posthuma CC, van der Meer Y, Bárcena M, Haagmans BL, Snijder EJ, van den 
bioRxiv preprint doi: https://doi.org/10.1101/2021.07.21.453304; this version posted July 22, 2021. The copyright holder for this preprint (which

was not certified by peer review) is the author/funder, who has granted bioRxiv a license to display the preprint in perpetuity. It is made available under aCC-BY-NC-ND 4.0 International license.

Hoogen BG. 2013. MERS-coronavirus replication induces severe in vitro cytopathology and is strongly inhibited by cyclosporin A or interferon- $\alpha$

744 treatment. J Gen Virol 94:1749-1760. 


\section{Figure legends}

FIG 1. Characterization of a SARS-CoV-2 infection model using air-liquid interface

750 individual donors were cultured for 5 weeks at ALI before they were infected with

751 SARS-CoV-2 (30,000 PFU per insert). (A) The viral load at 24, 48 and 72 hpi in cultures

752 was determined by quantifying the number of extracellular viral RNA copies by RT-

753 qPCR. The open circle represents the amount of (input) viral RNA that remained after

754 washing the inserts at $2 \mathrm{hpi}$. Data are mean \pm SEM. $\mathrm{n}=4$ independent experiments with

755 the same donor mix. (B) For immunofluorescence microscopy, cells were fixed at 72 hpi

756 and (double) labelled with rabbit polyclonal anti-SARS-CoV-2 N protein antibody

757 (JUC3) and with 4',6-diamidino-2-phenylindole (DAPI) for nuclear staining. Images

758 shown at $400 \mathrm{x}$ original magnification are representative for results obtained with cells

759 from 3 independent experiments. (C-D) The viral load in cultures derived from single

760 donors or the mix of these donors (blue) was determined by quantifying the number of

761 extracellular viral RNA copies by RT-qPCR. The infected cells in the cultures were

762 visualized by immunofluorescence microscopy at 72 hpi. (E-H) Analysis of gene

763 expression of IFNB1 (E), IFNL1 (F), IL-6 and CXCL8 (IL-8) (G), ACE2 and TMPRSS2

$764(\mathrm{H})$ normalized to two reference genes (RPL13A/ATP5B) in mixes of 5 donors by RT-

765 qPCR. The graphs represent the mRNA levels at $72 \mathrm{hpi}$. Data are mean values \pm SEM.

$766 \mathrm{n}=3$ independent experiments derived from the same donor mix cultured for at least 4

767 weeks in $\mathrm{E}$ and $\mathrm{F}$, and $\mathrm{n}=5$ independent experiments derived from the same donor mix

768 and 2 individual donors cultured for at least 4 weeks in G and H. Statistical analysis was

769 conducted using two-way ANOVA with a Tukey/Bonferroni post-hoc test. Significant

770 differences are indicated by $* \mathrm{P}<0.05$. 
776 FIG 2. Effects of culture duration on SARS-CoV-2 infection in PTEC and PBEC.

777 ALI-PBEC/ALI-PTEC (mix of 5 donors) cultured for 3-5 weeks were infected with

778 SARS-CoV-2 (30,000 PFU per insert). (A) Extracellular viral RNA copies in the apical

779 wash or (C) intracellular copies were measured by RT-qPCR. (B) Viral infectious

780 progeny was determined by plaque assay in Vero E6 cells. Mean values \pm SEM is

781 presented from 3 independent experiments using 3 different donor mixes. Statistical

782 analysis was conducted using two-way ANOVA with a Tukey/Bonferroni post-hoc test.

783 Significant differences are indicated by $* \mathrm{P}<0.05$. (D) Cells were immunofluorescence

784 stained with rabbit polyclonal anti-SARS-CoV-2 N protein antibody (JUC3) and DAPI

785 for nuclear staining. Images shown are representative for results obtained with ALI-

786 PBEC and ALI-PTEC from the same 3 independent experiments shown in A-C at $400 \mathrm{x}$

787 original magnification.

788 FIG 3. Cell types infected by SARS-CoV-2 in ALI-PBEC. ALI-PBEC (mix of 5 789 donors) cultured for 5 weeks were infected with SARS-CoV-2 (30,000 PFU per insert).

790 Immunofluorescence staining at 72 hpi with primary antibodies against acetylated $\alpha$ 791 tubulin as a ciliated cell marker (A) or MUC5AC as a goblet cell marker (B) in 792 combination with anti-SARS-CoV-2 N protein antibody (JUC3) and DAPI for nuclear 793 staining. Immunofluorescence images shown are representative for results of 3 794 independent experiments derived from the same donor mix with $630 \mathrm{x}$ original 795 magnification. White arrows indicate cells that display both green and red labelling.

797 FIG 4. Effect of culture duration on epithelial differentiation markers in PTEC and

798 PBEC. ALI-PTEC/PBEC (mix of 5 donors) were differentiated at ALI for 3, 4 or 5

799 weeks, fixed and analyzed by immunofluorescence microscopy (A) using antibodies

800 against acetylated $\alpha$-tubulin and FOXJ1 (ciliated cell markers) or MUC5AC (goblet cell

801 marker) in combination with DAPI for nuclear staining. Images shown are representative

802 for results of 3 independent experiments with 100x/400x (insert) original magnification.

803 (B) Quantification of FOXJ-positive cells and MUC5AC-positive cells was done by 804 Image J software. (C) mRNA levels of FOXJ1 and MUC5AC were measured by RT805 qPCR. $\mathrm{n}=3$ independent experiments derived from 3 different donor mixes same as in 
806 FIG 2. Data are mean \pm SEM. Analysis of differences was conducted using two-way

807 ANOVA with a Tukey/Bonferroni post-hoc test. Significant differences are indicated by

$808 * \mathrm{P}<0.05$.

811 FIG 5. Effect of IL-13 treatment, and DAPT-mediated inhibition of Notch signaling 812 on epithelial susceptibility to SARS-CoV-2 infection. ALI-PBEC (mix of 4-5 donors)

813 were differentiated for 3 weeks, before addition of DAPT $(5 \mu \mathrm{M})$ or IL-13 $(1 \mathrm{ng} / \mathrm{ml})$ and

814 differentiation for an additional 2 weeks. (A) After in total 5 weeks of differentiation,

815 ALI-PBEC were fixed, stained using primary antibodies against MUC5AC and FOXJ1

816 (goblet cell marker, ciliated cell marker) or acetylated $\alpha$-tubulin together with FOXJ1

817 (ciliated cell markers) in combination with DAPI for nuclear staining and analyzed by

818 immunofluorescence microscopy. (B) SARS-CoV-2 infected cells were stained with

819 primary antibodies against SARS-CoV-2 N protein (JUC3) in combination with DAPI for

820 nuclear staining. (C) Intracellular viral RNA copies were measured by RT-qPCR and

821 their fold change in treated cultures compared to untreated controls was determined. (D)

822 Plaque assay was performed to titrate viral progeny in the apical washes. $n=3$

823 independent experiments derived from 3 different donor mixes. Data are mean \pm SEM.

824 Analysis of differences was conducted using two-way ANOVA with a Tukey/Bonferroni

825 post-hoc test. Significant differences are indicated by $* \mathrm{P}<0.05$ compared with untreated 826 samples.

829 FIG 6. Effect of culture duration on expression of SARS-CoV-2 cell-entry related

830 factors in well-differentiated primary epithelial cells. ALI-PBEC/PTEC cultured for 3-

8315 weeks with or without the presence of DAPT/IL-13 (during the last 2 weeks) were 832 infected with SARS-CoV-2 (30,000 PFU per insert). Expression of ACE2, TMPRSS2, 833 CH147 and GRP78 over time (A) or in DAPT/IL-13 treated cultures (B) were measured 834 by RT-qPCR. $\mathrm{n}=3$ independent experiments using 3 different donor mixes. Data are mean 835 values \pm SEM. Analysis of differences was conducted using two-way ANOVA with a 836 Tukey/Bonferroni post-hoc test or paired t test. 
838 FIG 7. Antiviral responses after SARS-CoV-2 infection. ALI-PTEC/PBEC cultured

839 for 3-5 weeks (A-D), and 5-week ALI-PBEC (E, F) cultured at ALI with or without the

840 presence of DAPT/IL-13 (during the last 2 weeks), were infected by SARS-CoV-2

841 (30,000 PFU per insert). Cells were lysed at 72 hpi to quantify mRNA levels of IFNB1

$842(\mathrm{~A} / \mathrm{C} / \mathrm{E})$ and IFNL1 (B/D/F) by RT-qPCR. $\mathrm{n}=3$ independent experiments using 3 different

843 donor mixes. Data are mean \pm SEM. Fold change in E and F was compared to untreated

844 controls. Analysis of differences was conducted using two-way ANOVA with a

845 Tukey/Bonferroni post-hoc test. Significant differences are indicated by $* \mathrm{P}<0.05$.

846 


\section{Supplementary figures}

849 Supplementary Figure 1. Effect of culture duration on SARS-CoV-2 viral load in

850 ALI-PTEC and ALI-PBEC cultures. ALI-PBEC/ALI-PTEC (mix of 5 donors) cultured

851 for 3-5 weeks at ALI were infected with SARS-CoV-2 (30,000 PFU per insert). (A)

852 Extracellular viral RNA copies in the apical wash were measured by RT-qPCR. (B)

853 Plaque assay was performed to quantify infectious virus titers in ALI-PBEC or ALI-

854 PTEC. Data are shown as mean \pm SEM. Three different donor mixes (1-3) from ALI-

855 PBEC/PTEC were included, each containing biological duplicates.

858 Supplementary Figure 2. Cell types infected by SARS-CoV-2 in ALI-PTEC. Cells

859 (mix of 5 donors) cultured for 5 weeks were infected with SARS-CoV-2 (30,000 PFU per

860 insert). At 72 hpi, cells were fixed and stained with antibodies against acetylated $\alpha$ -

861 tubulin (ciliated cell marker, A) or MUC5AC (goblet cell marker, B) in combination with

862 anti-SARS-CoV-2 $\mathrm{N}$ protein antibody (JUC3) and DAPI for nuclear staining.

863 Immunofluorescence images shown are representative for results of 3 independent

864 experiments with $630 \mathrm{x}$ original magnification. White arrows indicate cells that show co-

865 staining of cell markers and viral $\mathrm{N}$ protein.

868 Supplementary Figure 3. Effect of culture duration on expression of epithelial cell869 specific genes by PTEC and PBEC cultures. ALI-PTEC/PBEC (mix of 5 donors) were 870 differentiated at ALI for 2, 3, 4 or 5 weeks, and analyzed by RT-qPCR to measure gene 871 expression of SCGB1A1 (club cell marker) and TP63 (basal cell marker). n=2 872 independent experiments at week 2 and $n=3$ independent experiments at 3-5 weeks 873 derived from three donor mixes the same as infection cultures. Data are mean \pm SEM. 874 Analysis of differences was conducted using two-way ANOVA with a Tukey/Bonferroni 875 post-hoc test. Significant differences are indicated by $* \mathrm{P}<0.05$. 
878 Supplementary Figure 4. Effect of long-term DAPT/IL-13 exposure on epithelial cell 879 composition and effect of acute DAPT/IL-13 exposure on susceptibility to SARS-

880 CoV-2 infection. ALI-PBEC (mix of 4-5 donors) were differentiated for 3 weeks, before 881 addition of DAPT $(5 \mu \mathrm{M})$ or IL-13 (1 $\mathrm{ng} / \mathrm{ml})$, followed by differentiation for an 882 additional 2 weeks. (A) After 5 weeks of differentiation, ALI-PBEC were fixed, stained 883 and analyzed by immunofluorescence using primary antibodies against MUC5AC and 884 FOXJ1 (goblet cell marker, ciliated cell marker) or acetylated $\alpha$-tubulin together with 885 FOXJ1 (both ciliated cell markers) in combination with DAPI for nuclear staining. The 886 quantification of FOXJ1-positive cells and MUC5AC-positive cells was done by ImageJ 887 software. Data are mean \pm SEM. (B) mRNA levels of FOXJ1 and MUC5AC were 888 measured by RT-qPCR. Data are mean \pm SEM. Analysis of differences was conducted 889 using paired t test. (C) Short-term treatment with DAPT was performed in cells after 5 890 weeks of differentiation. Cells were either pre-treated with DAPT for $24 \mathrm{~h}$ (Pre891 treatment) or post-treated directly after infection (Post-treatment). Intracellular SARS-

892 CoV-2 RNA copies were measured by RT-qPCR and plaque assay was performed with 893 apical washes to quantify infectious virus titers. $n=3$ independent experiments. Data are 894 mean \pm SEM. Fold change in intracellular RNA copies was compared to untreated 895 controls. Statistical analysis was performed using a paired t test. Significant differences 896 are indicated by $* \mathrm{P}<0.05$. 


\section{FIG 1}

A

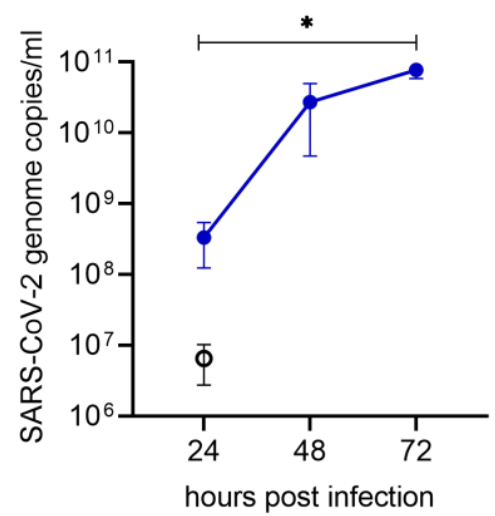

C

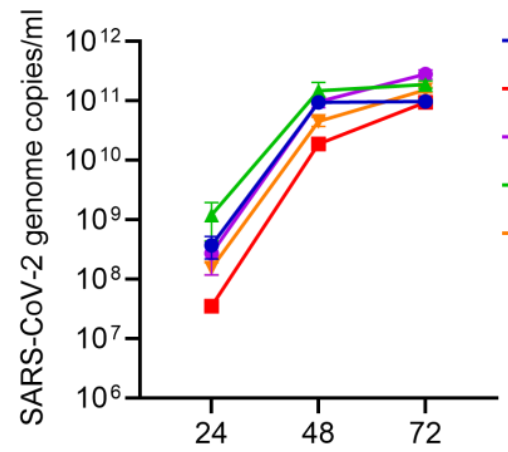

hours post infection

$E$

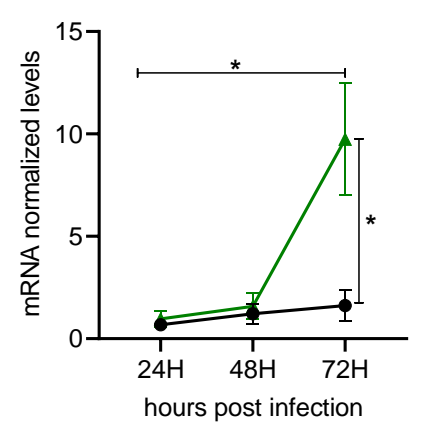

G

IL-6
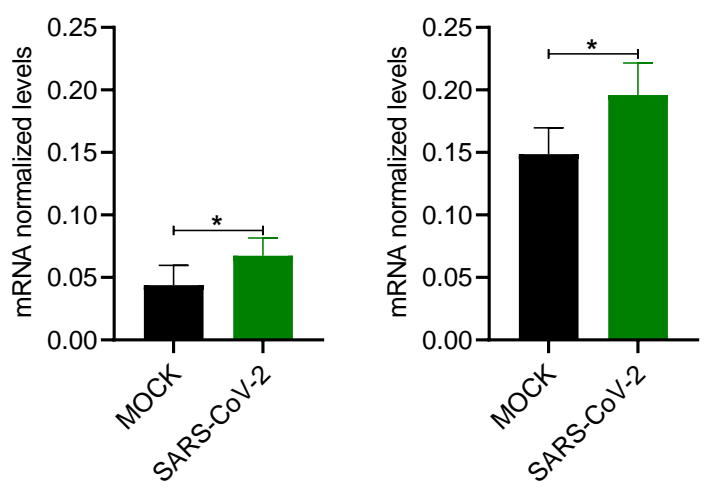

$\rightarrow$ MOCK
B

$24 \mathrm{~h}$

$48 \mathrm{~h}$

$72 \mathrm{~h}$

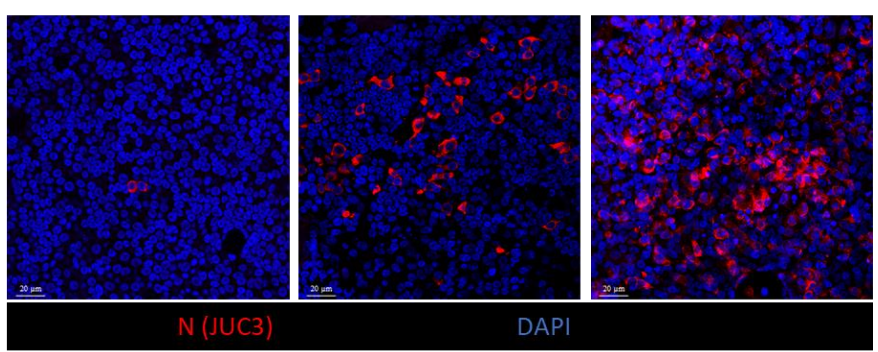

Donor 1

Donor 2

Donor 3

D

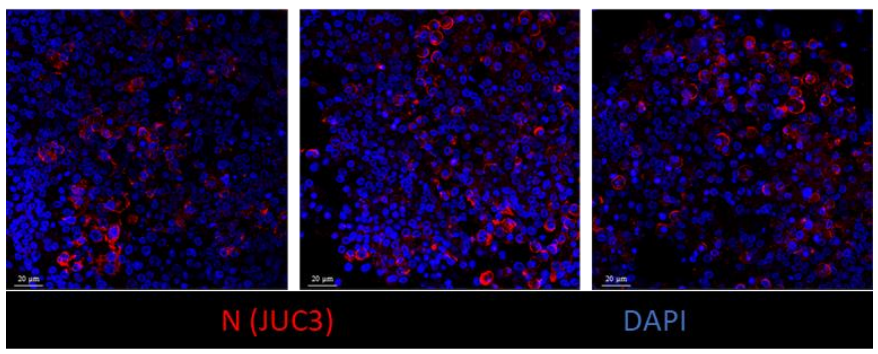

Donor 4

Donor mix
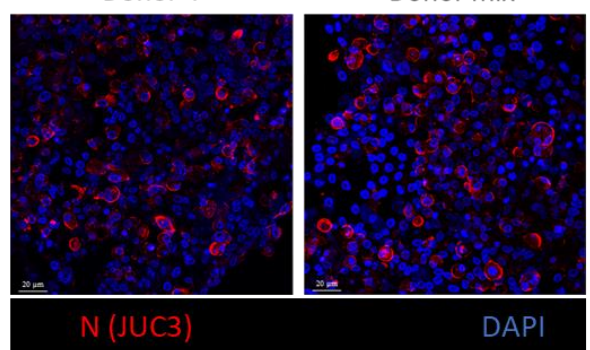

F

IFNL1

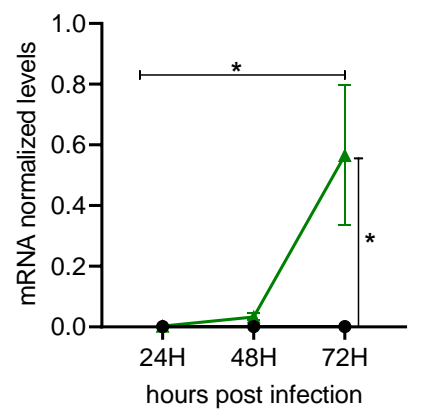

$\rightarrow$ MOCK

$\rightarrow$ SARS-CoV-2

$\mathrm{H}$

ACE2

TMPRSS2
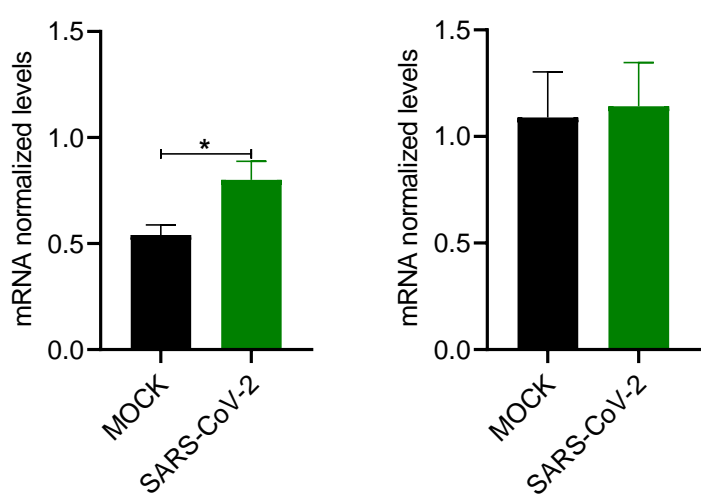


\section{FIG 2}

A

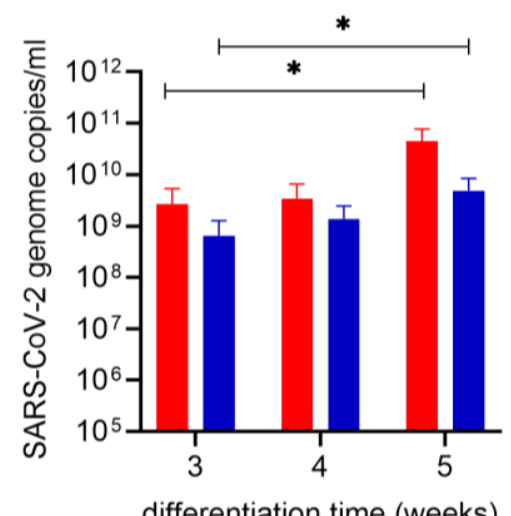

C

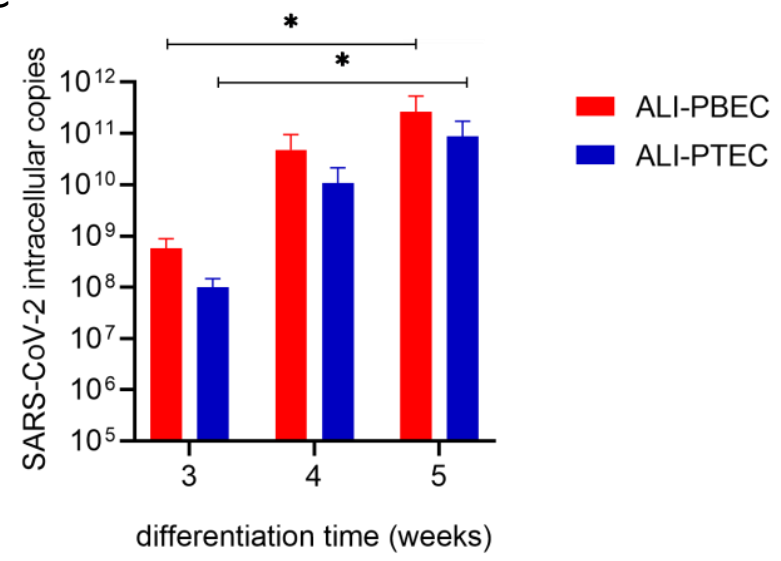

ALI-PBEC

ALI-PTEC
B

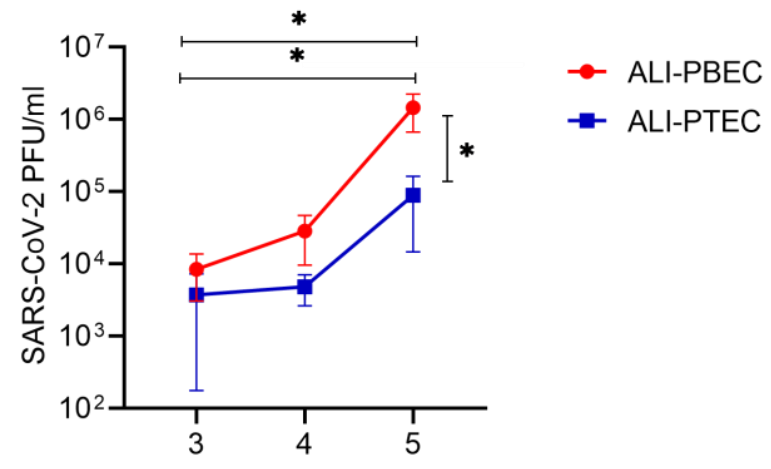

differentiation time (weeks)

D

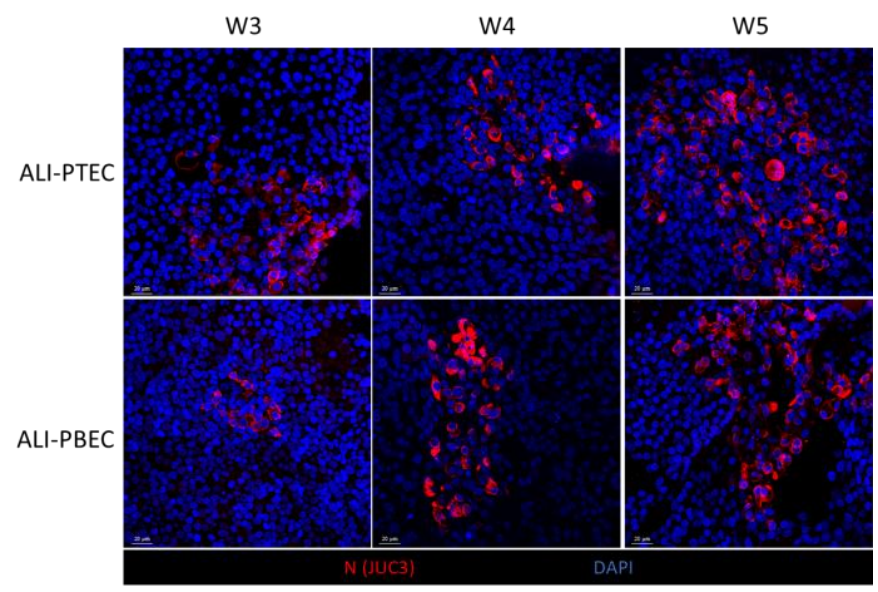




\section{FIG 3}

A

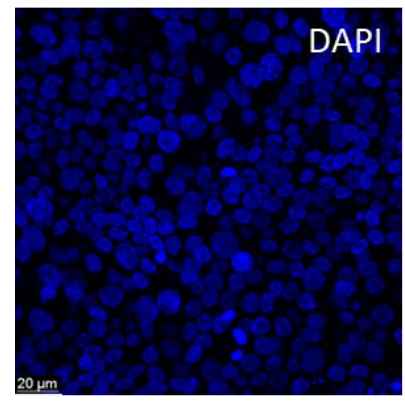

$72 \mathrm{~h}$ after infection in 5-week ALI-PBEC
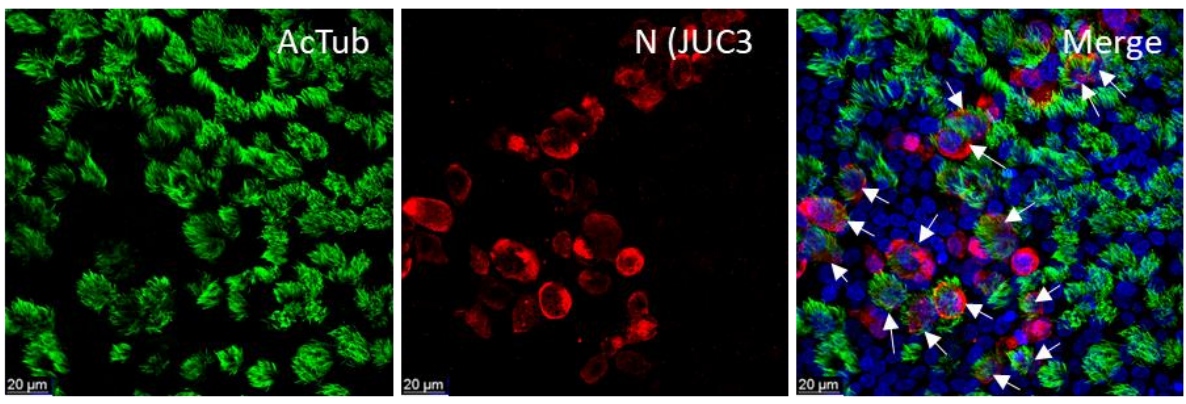

$72 \mathrm{~h}$ after infection in 5-week ALI-PBEC

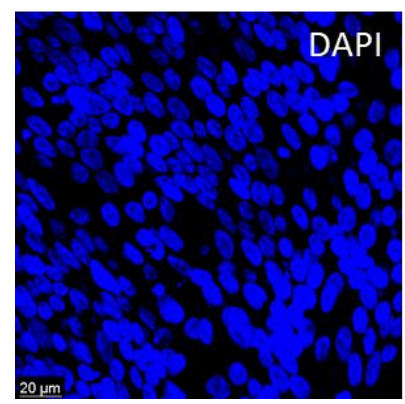

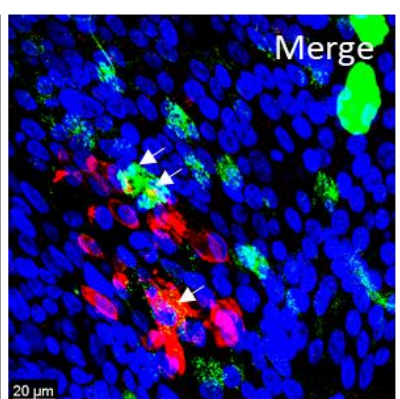




\section{FIG 4}

A
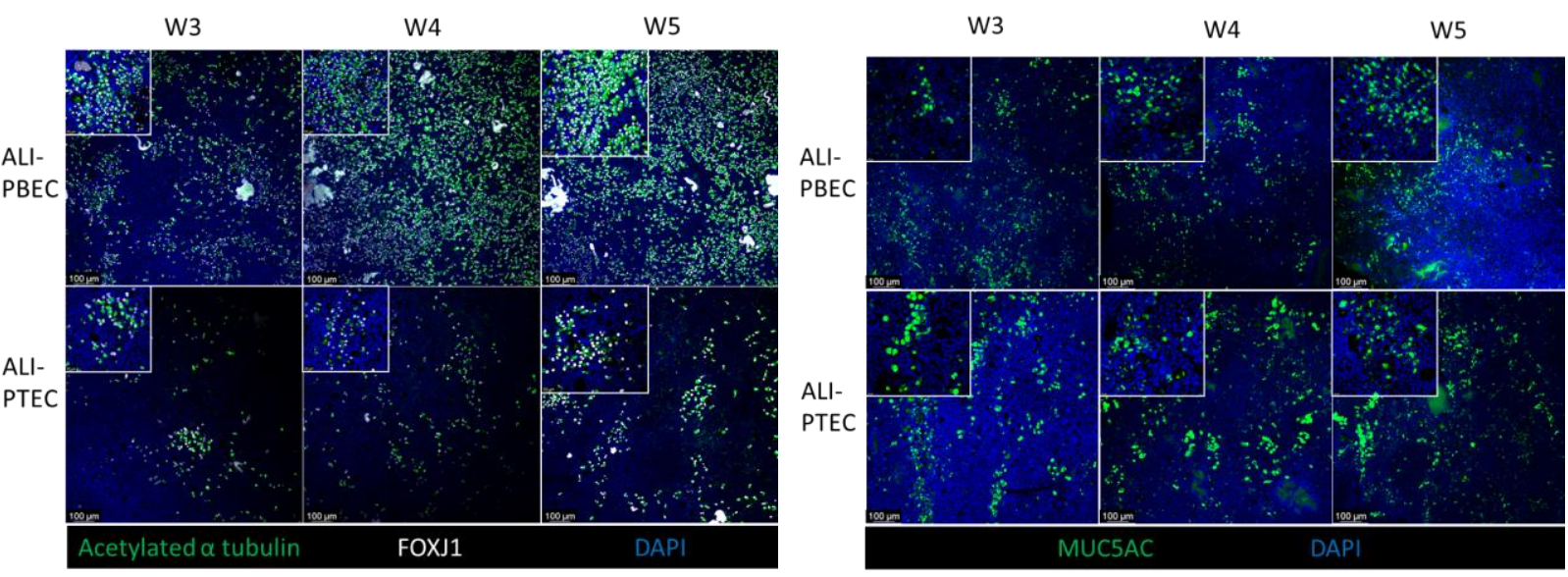

B
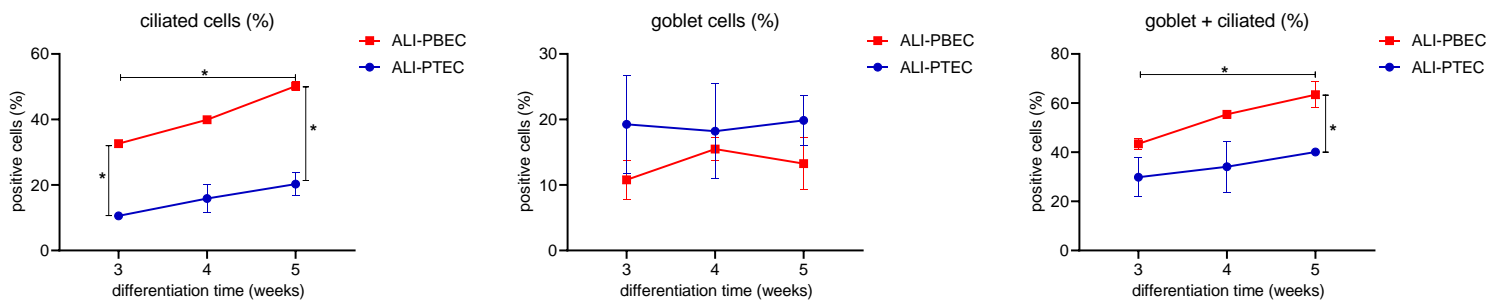

C
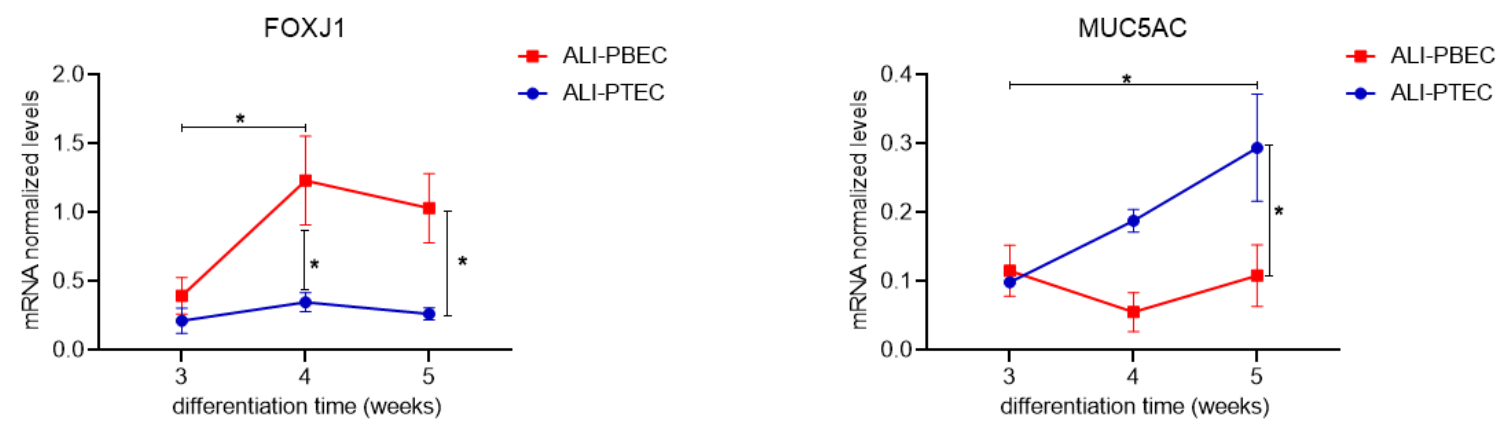


\section{FIG 5}

A

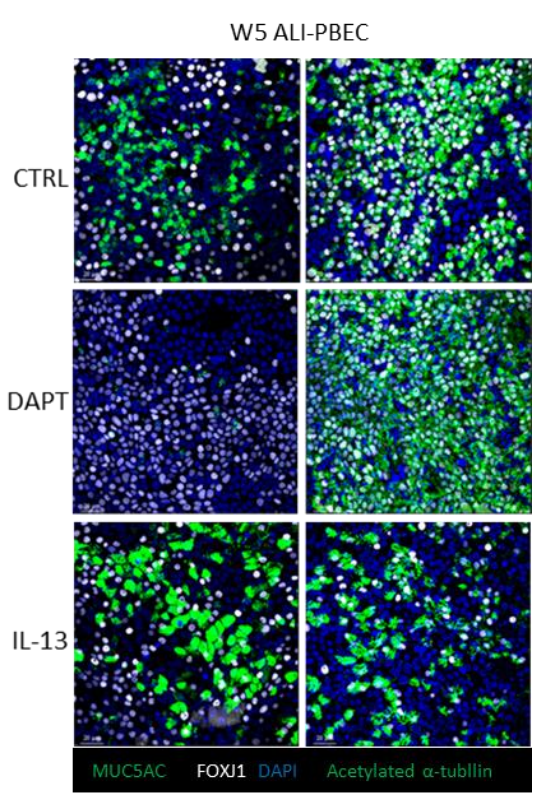

C

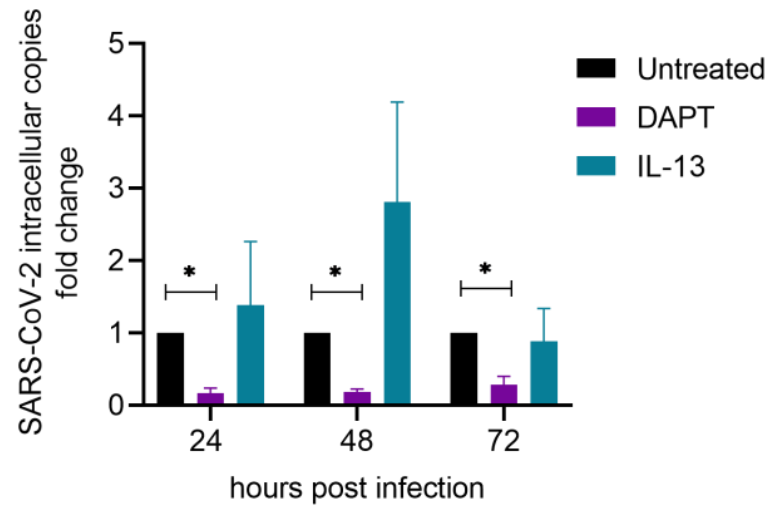

B
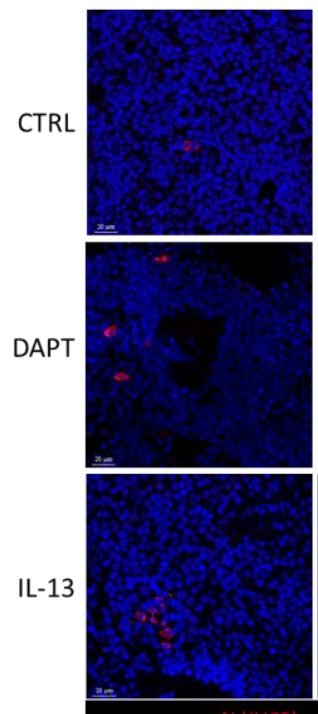

$48 \mathrm{~h}$

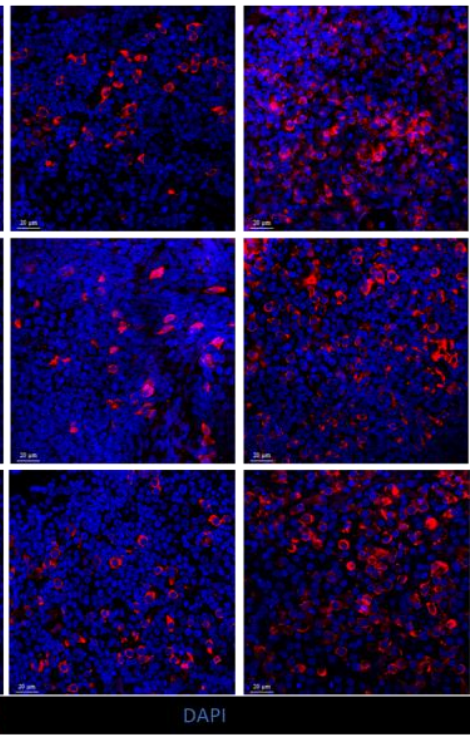

D

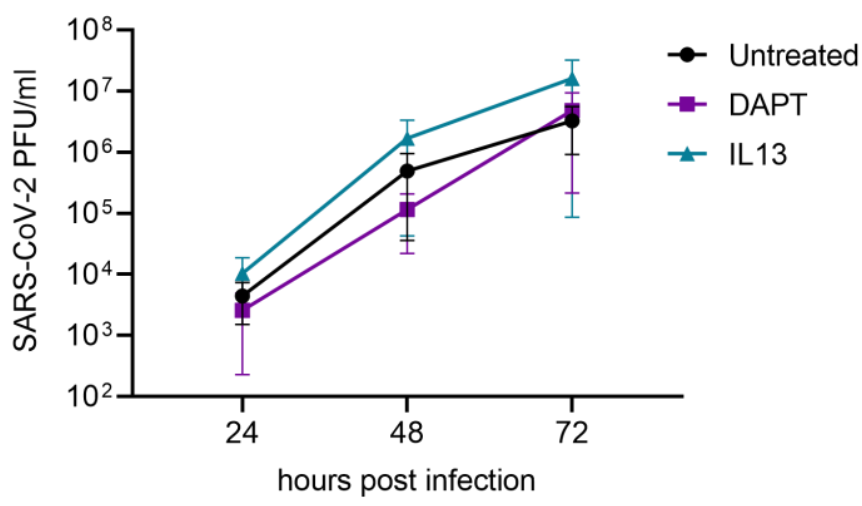




\section{FIG 6}

A

- ALI-PBEC

ACE2

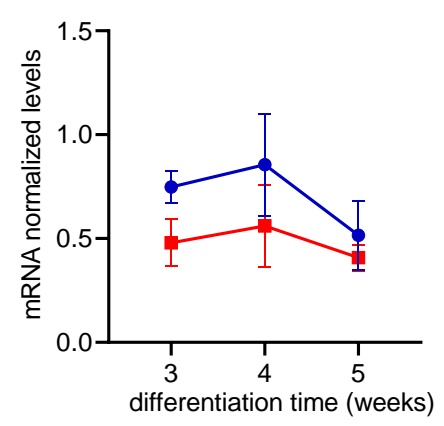

CD147

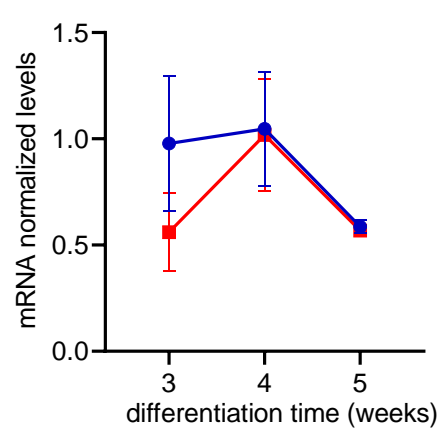

B

ACE2

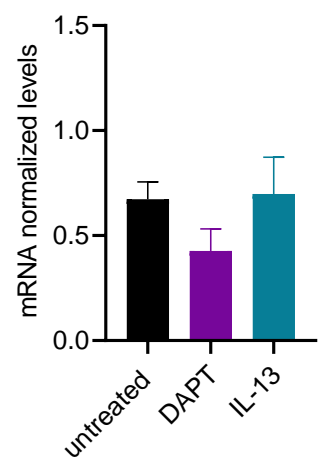

CD147

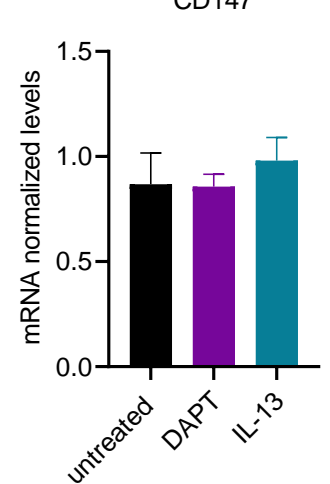

TMPRSS2
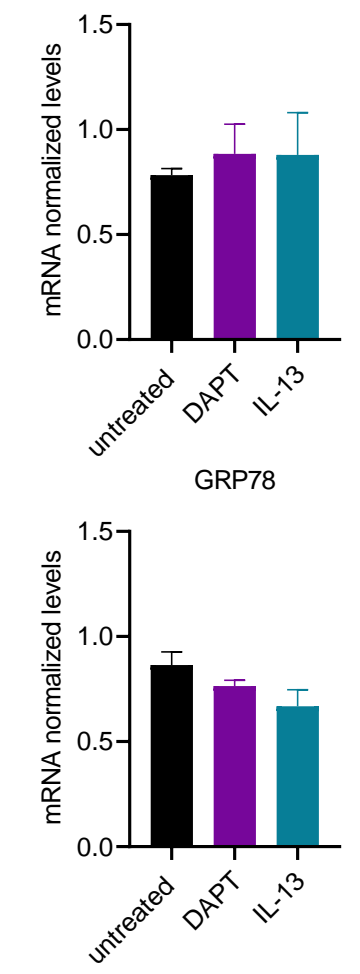

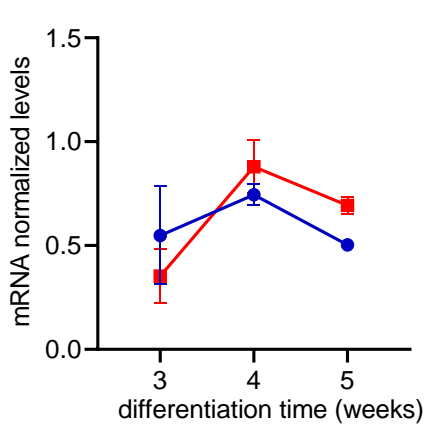

GRP78

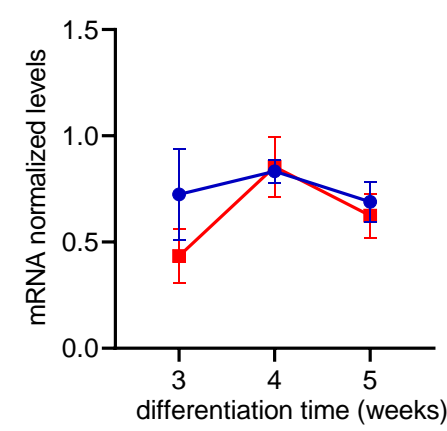




\section{FIG 7}

A

IFN B1

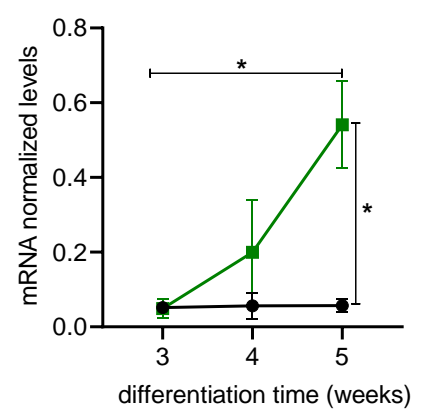

C

IFN B1

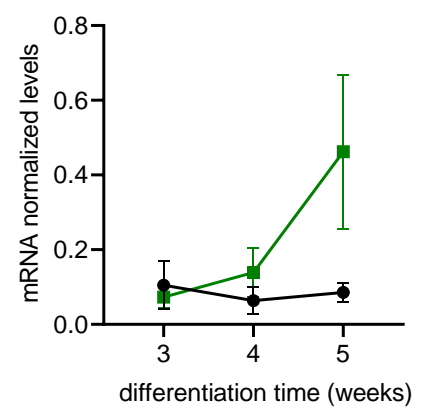

$\mathrm{E}$

IFN B1 after infection

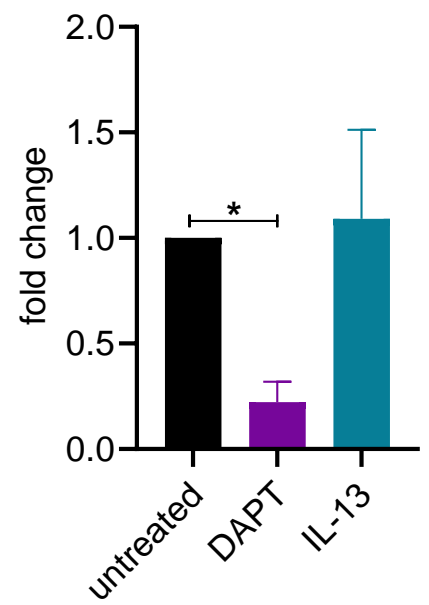

ALI-PTEC

- MOCK
- SARS-CoV-2

ALI-PBEC

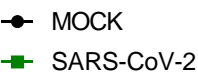

$=$ SARS-CoV-2
IFN L1

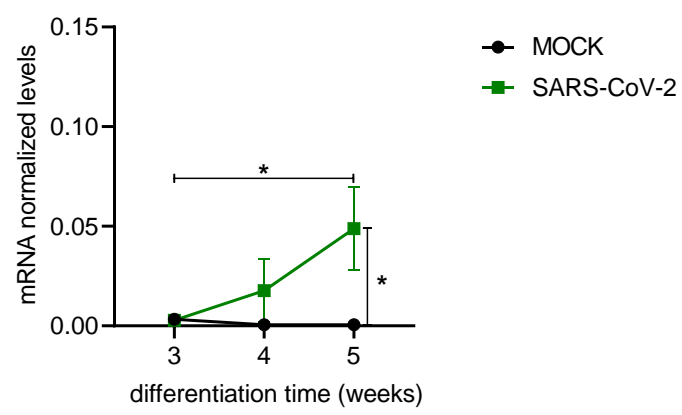

IFN L1

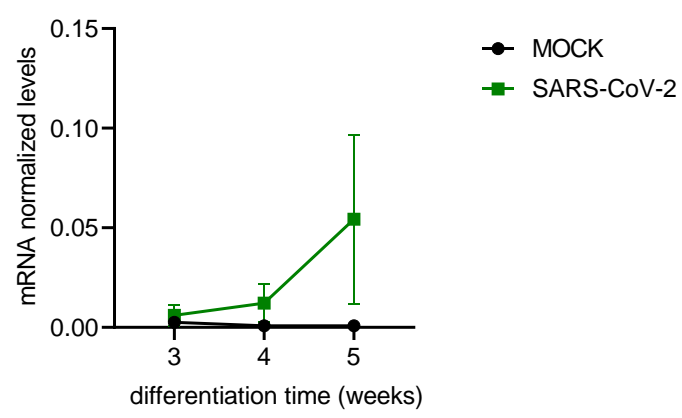

$\mathrm{F}$

IFN L1 after infection

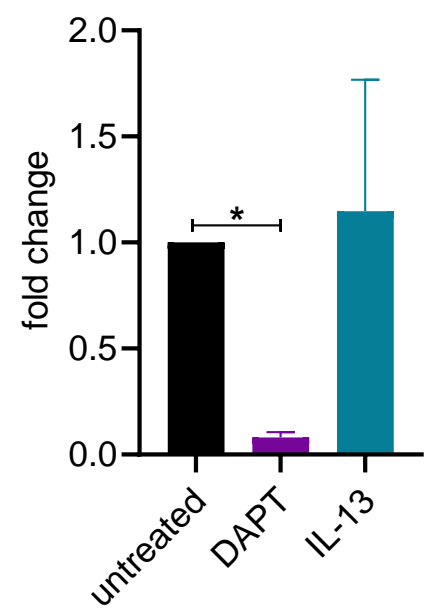


bioRxiv preprint doi: https://doi.org/10.1101/2021.07.21.453304; this version posted July 22, 2021. The copyright holder for this preprint (which was not certified by peer review) is the author/funder, who has granted bioRxiv a license to display the preprint in perpetuity. It is made

Table 1 Primer sequences available under aCC-BY-NC-ND 4.0 International license.

\begin{tabular}{|c|c|c|}
\hline Gene & Forward primer (5'-3') & Reverse primer (5'-3') \\
\hline $\mathrm{E}$ & $\begin{array}{l}\text { ACAGGTACGTTAATAGTTAATAGC } \\
\text { GT }\end{array}$ & ATATTGCAGCAGTACGCACACA \\
\hline E probe & \multicolumn{2}{|c|}{ TexRed-ACACTAGCCATCCTTACTGCGCTTCG-BHQ1 } \\
\hline $\operatorname{RdRp}$ & GTGARATGGTCATGTGTGGCGG & $\begin{array}{l}\text { CARATGTTAAASACACTATTAGCA } \\
\text { TA }\end{array}$ \\
\hline $\begin{array}{l}\text { RdRp } \\
\text { probe }\end{array}$ & \multicolumn{2}{|c|}{ FAM-CAGGTGGAACCTCATCAGGAGATGC-BHQ1 } \\
\hline $\begin{array}{l}\text { MUC5A } \\
\text { C }\end{array}$ & CCTTCGACGGACAGAGCTAC & TCTCGGTGACAACACGAAAG \\
\hline FOXJ1 & GGAGGGGACGTAAATCCCTA & TTGGTCCCAGTAGTTCCAGC \\
\hline $\begin{array}{l}\text { SCGB1A } \\
1\end{array}$ & ACATGAGGGAGGCAGGGGCTC & ACTCAAAGCATGGCAGCGGCA \\
\hline TP63 & CCACCTGGACGTATTCCACTG & TCGAATCAAATGACTAGGAGGGG \\
\hline IFNL1 & GGACGCCTTGGAAGAGTCACT & AGAAGCCTCAGGTCCCAATTC \\
\hline IFNB1 & ATGACCAACAAGTGTCTCCTCC & GGAATCCAAGCAAGTTGTAGCTC \\
\hline CXCL8 & CTGGACCCCAAGGAAAAC & TGGCAACCCTACAACAGAC \\
\hline IL6 & CAGAGCTGTGCAGATGAGTAC A & GATGAGTTGTCATGTCCTGCA \\
\hline ACE2 & CGTCTGAATGACAACAGCCTAGA & AATGCCAACCACTATCACTCCC \\
\hline $\begin{array}{l}\text { TMPRSS } \\
2\end{array}$ & AATCGGTGTGTTCGCCTCTAC & CGTAGTTCTCGTTCCAGTCGT \\
\hline CD147 & CAGAGTGAAGGCTGTGAAGTCG & TGCGAGGAACTCACGAAGAAC \\
\hline
\end{tabular}


bioRxiv preprint doi: https://doi.org/10.1101/2021.07.21.453304; this version posted July 22, 2021. The copyright holder for this preprint (which was not certified by peer review) is the author/funder, who has granted bioRxiv a license to display the preprint in perpetuity. It is made

\begin{tabular}{|c|c|c|}
\hline GRP78 & 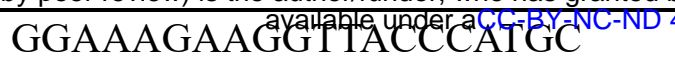 & AGAAGAGACACATCGAAGGT \\
\hline АТР5B & TCACCCAGGCTGGTTCAGA & AGTGGCCAGGGTAGGCTGAT \\
\hline RPL13A & AAGGTGGTGGTCGTACGCTGTG & CGGGAAGGGTTGGTGTTCATCC \\
\hline
\end{tabular}

